Delft University of Technology

\title{
Synthesis and characterization of SnO2 crystalline nanoparticles: A new approach for enhancing the catalytic ozonation of acetaminophen
}

Rashidashmagh, Fatemeh; Doekhi-Bennani, Yasmina; Tizghadam-Ghazani, Mostafa; Hoek, Jan Peter van der; Mashayekh-Salehi, Ali; Heijman, Bas S.G.J.; Yaghmaeian, Kamyar

DOI

10.1016/j.jhazmat.2020.124154

Publication date

2021

Document Version

Final published version

Published in

Journal of Hazardous Materials

\section{Citation (APA)}

Rashidashmagh, F., Doekhi-Bennani, Y., Tizghadam-Ghazani, M., Hoek, J. P. V. D., Mashayekh-Salehi, A., Heijman, B. S. G. J., \& Yaghmaeian, K. (2021). Synthesis and characterization of SnO2 crystalline nanoparticles: A new approach for enhancing the catalytic ozonation of acetaminophen. Journal of Hazardous Materials, 404, 124154. [124154]. https://doi.org/10.1016/j.jhazmat.2020.124154

Important note

To cite this publication, please use the final published version (if applicable).

Please check the document version above.

\section{Copyright}

Other than for strictly personal use, it is not permitted to download, forward or distribute the text or part of it, without the consent of the author(s) and/or copyright holder(s), unless the work is under an open content license such as Creative Commons.

\section{Takedown policy}

Please contact us and provide details if you believe this document breaches copyrights.

We will remove access to the work immediately and investigate your claim. 
Green Open Access added to TU Delft Institutional Repository

'You share, we take care!' - Taverne project

https://www.openaccess.nl/en/you-share-we-take-care

Otherwise as indicated in the copyright section: the publisher is the copyright holder of this work and the author uses the Dutch legislation to make this work public. 


\title{
Synthesis and characterization of $\mathrm{SnO}_{2}$ crystalline nanoparticles: A new approach for enhancing the catalytic ozonation of acetaminophen
}

\author{
Fatemeh Rashidashmagh ${ }^{\mathrm{a}}$, Yasmina Doekhi-Bennani ${ }^{\mathrm{b}}$, Mostafa Tizghadam-Ghazani ${ }^{\mathrm{a}, *}$, \\ Jan Peter van der Hoek ${ }^{\mathrm{b}}$, Ali Mashayekh-Salehi ${ }^{\text {c, }}$, Bas S.G.J. Heijman ${ }^{\mathrm{b}}$, Kamyar Yaghmaeian ${ }^{\mathrm{d}}$ \\ ${ }^{a}$ Water and Environmental Engineering faculty, Shahid Beheshti University, Tehran, Iran \\ ${ }^{\mathrm{b}}$ Department of Water Management, Delft University of Technology, Delft, The Netherlands \\ ${ }^{\mathrm{c}}$ School of Public Health, Shahroud University of Medical Sciences, Shahroud, Iran \\ ${ }^{\mathrm{d}}$ Department of Environmental Health Engineering, Faculty of Health, Tehran University of Medical Sciences, Tehran, Iran
}

\section{A R T I C L E I N F O}

\section{Keywords:}

Emerging pollutants

Catalytic ozonation

$\mathrm{SnO}_{2}$ nanoparticles

Sol-gel

Acetaminophen (ACT)

\begin{abstract}
A B S T R A C T
A novel sol-gel method was employed in this study to efficiently synthesize $\mathrm{SnO}_{2}$ nanoparticles to catalyze the ozonation of acetaminophen (ACT) from aqueous solutions. The influence of various parameters including Sn source, type of capping and alkaline agents, and calcination temperature on the catalytic activity of the $\mathrm{SnO}_{2}$ preparations was investigated. The $\mathrm{SnO}_{2}$ nanoparticles prepared by tin tetrachloride as $\mathrm{Sn}$ source, $\mathrm{NaOH}$ as gelatin agent, $\mathrm{CTAB}$ as capping agent and at calcination temperature of $550{ }^{\circ} \mathrm{C}$ (SnNaC-550) exhibited the maximum performance in the catalysis of ACT. The optimized catalyst (SnNaC-550) had spherical-homogeneous and cubic-shaped nanocrystalline particles with $5.5 \mathrm{~nm}$ mean particle size and a BET surface area of $81 \mathrm{~m}^{2} / \mathrm{g}$, which resulted in $98 \%$ degradation and $84 \%$ mineralization of $50 \mathrm{mg} / \mathrm{L} \mathrm{ACT}$ at 20 and 30 min reaction time, respectively when combined with ozonation (COP). Based on the radical scavenger experiments, ${ }^{\circ} \mathrm{OH}$ was the major oxidizing agent involved in the removal of ACT. LC/MS analysis showed that short-chain carboxylic acids were the main intermediates. Furthermore, the SnNaC-550 catalytic activity was preserved after four successive cycles. Collectively, the new method has the potential to efficiently synthesize stable and reusable $\mathrm{SnO}_{2}$ nanoparticles to catalyze the ozonation of ACT from aquatic environments.
\end{abstract}

\section{Introduction}

In the last decades, the rapid global population growth, urbanization, industrialization, commercialization and several anthropogenic activities have resulted into the generation of a new category of micropollutants known as emerging contaminants (ECs). These compounds have the potential to impose hazardous effects on both ecosystem and human health (Meffe and de Bustamante, 2014). A large body of evidences highlights that different concentrations of ECs ranging from ng/L to $\mathrm{mg} / \mathrm{L}$ are found in water sources and wastewater effluents (Petrie et al., 2015; Taheran et al., 2018; Shah et al., 2020; Ramírez-Malule et al., 2020; Hartmann et al., 2019; Luo et al., 2014; Hartmann et al., 2020; Rout et al., 2021; Houtman et al., 2014). ECs can be subdivided into the different groups of contaminants including pesticides, endocrine disrupting compounds (EDCs), industrial compounds, cosmetics, and pharmaceutical compounds (PCs) (Gogoi et al., 2018). Among the mentioned agents, PCs are a diverse group of chemicals that are widely consumed throughout the world (Yang et al., 2017). These compounds are largely excreted non-metabolized into the urine and feces, and eventually end up in wastewaters (Esplugas et al., 2007). These claims are supported by the numerous evidences showing various amounts of PCs in water bodies worldwide (Ebele et al., 2017). Since the presence of PCs in water resources, even at trace amounts, could negatively impact the health of humans as well the wildlife and living microorganisms in aquatic environments, therefore these pollutants should appropriately be removed from waters and wastewaters (Nikolaou et al., 2007).

The biorecalcitrant pollutants, such as PCs, are only removed partially by the conventional wastewater treatment processes (Kanakaraju et al., 2018; Luján-Facundo et al., 2019), accordingly, advanced techniques are needed to achieve a complete degradation of these

\footnotetext{
* Corresponding authors.

E-mail addresses: f_rashid@sbu.ac.ir (F. Rashidashmagh), Y.Doekhi-Bennani@tudelft.nl (Y. Doekhi-Bennani), m_tizghadam@sbu.ac.ir (M. Tizghadam-Ghazani),

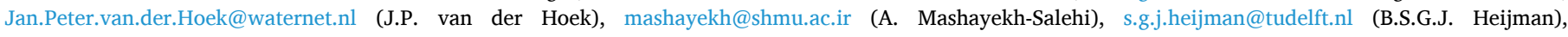
kyaghmaeian@tums.ac.ir (K. Yaghmaeian).
} 
persistent contaminants. Among the various new technologies have been developed (Mashayekh-Salehi and Moussavi, 2016; Ensano et al., 2017; Radjenović et al., 2009; Shariati et al., 2010; Escolà Casas et al., 2015; Tambosi et al., 2010), ozone based-advanced oxidation processes (AOPs) are recommended for water treatment in view of PCs removal (Klavarioti et al., 2009; Feng L., 2014). Previous studies have shown that the use of sole ozonation process (SOP) has great advantages in removing odor and color, however is not particularly effective in eliminating PCs (Saeid et al., 2018; Wang and Bai, 2017). Ozone reacts in two ways: 1) in its molecular form, which is selective, and 2) through the generation of radicals, which is highly dependent on the $\mathrm{pH}$ value of the medium. Moreover, several disadvantages including incomplete oxidation of contaminants, low rate of mass transfer, high operational cost and low stability and solubility in aqueous environments have also been attributed to the individual ozonation process (Rivas et al., 2009).

In this regards, it has been shown that the addition of a catalyst to the ozonation, catalytic ozonation processes (COP), could improve the process performance through converting $\mathrm{O}_{3}$ into very active hydroxyl radicals $\left({ }^{\circ} \mathrm{OH}\right)$ that have an oxidation potential higher than the sole molecular ozone, thus increases the process capability in degradation and mineralization of pharmaceutical contaminants (Sui et al., 2012). According to the literature, several materials and metal oxides, including alumina-based catalysts $\left(\mathrm{Co}_{3} \mathrm{O}_{4} / \mathrm{Al}_{2} \mathrm{O}_{3}\right)$ (Pocostales et al., 2011), MgO (Mashayekh-Salehi et al., 2017; Moussavi and Mahmoudi, 2009), $\mathrm{SnO}_{2}$ (Begum and Ahmaruzzaman, 2018; Zeng et al., 2009), $\mathrm{Fe}^{2+}, \mathrm{Cu}^{2+}$ (Skoumal et al., 2006), carbon materials (Sui et al., 2012; Gonçalves et al., 2012), $\mathrm{TiO}_{2}$ (Rosal et al., 2008), NCNs (Khataee et al., 2017), $\mathrm{TiO}_{2}$ nanofibers (Gupta et al., 2018), iron-nickel foam (Huang et al., 2019), $\mathrm{MnO}_{2}$ (Nawaz et al., 2017), and ZnO-CN (Yuan et al., 2018), have widely been investigated combined with ozonation (COP) for removing several types of water contaminants. However, due to different disadvantages, research for finding powerful and cost-effective catalysts for the COP to treat a wide range of pollutants is still a continuous process. Among the mentioned catalysts, $\mathrm{SnO}_{2}$ has unique electrical and catalytic characteristics and stability, which makes it suitable material for catalytic applications (Begum and Ahmaruzzaman, 2018). It is a semiconductor material with a versatile large band gap energy $(3.6 \mathrm{eV}$ at $300 \mathrm{~K})$, high donor concentration as well as large mobility (Zeng et al., 2009; Cao et al., 2013). Due to these properties, some recent studies have tested $\mathrm{SnO}_{2}$ as a catalyst in the ozonation of different ECs. In this regards, Yu-Feng Zeng et al. (Zeng et al., 2009) has shown that the implementation of $\mathrm{SnO}_{2}$ as a catalyst in the COP could result in the generation of higher amounts of ${ }^{\circ} \mathrm{OH}$ species, even when used at low dosages. However, more research on $\mathrm{SnO}_{2}$ nanoparticle synthesis is still required to evaluate the influence of various parameters, such as Sn source, type of capping and alkaline agent, temperature of calcination on the capability of this catalyst in the COP for ECs removal from water.

Previous studies have mostly used hydrothermal methods, chemical precipitation, microwave and spray pyrolysis to synthesize $\mathrm{SnO}_{2}$ nanoparticles (Cao et al., 2013; Fu et al., 2011; Chang, 2019; Turgut and Sönmez, 2014). However, these techniques have some challenges of being high cost and harsh reaction conditions (Taghvaei et al., 2009; Gondal et al., 2010), thus new methods are required to efficiently synthesize $\mathrm{SnO}_{2}$ nanoparticles. However, based on a literature survey, it has not been found any previous study related to the synthesis of $\mathrm{SnO}_{2}$ by sol-gel method in the synthesis of $\mathrm{SnO}_{2}$ nanocomposites. The sol-gel is a simple cost-effective method which could attain high purity nano-sized $\mathrm{SnO}_{2}$ catalyst (Aziz et al., 2013; Kumar et al., 2015). In spite of the source of the catalyst (Deng et al., 2003; Dimitrov et al., 2010), there are other critical parameters including calcination temperature (Zhong et al., 2012), type/amount of alkaline agent (Journal C., 2003) and type and the presence of capping agent (Begum and Ahmaruzzaman, 2018), which could impact on the potential activity of the prepared catalyst. Hence, all these parameters were put into the consideration in this study to obtain an optimized $\mathrm{SnO}_{2}$ catalyst using the sol-gel method.
Paracetamol $\left(\mathrm{C}_{8} \mathrm{H}_{9} \mathrm{NO}_{2} ; \mathrm{N}\right.$-acetyl-4-aminophenol), commonly named Acetaminophen (ACT), is an example of pharmaceutical agent that has been extensively used with or without prescription mainly due to its analgesic and antipyretic properties. Previous studies have shown that about $58-68 \%$ of ACT at therapeutic dosage is excreted into the urine and feces (de Luna et al., 2013). This is in line with the numerous reports have detected ACT with concentration up to $0.38 \mu \mathrm{g} / \mathrm{L}$ in groundwater and 1.38-15.7 $\mu \mathrm{g} / \mathrm{L}$ in surface waters (Meffe and de Bustamante, 2014; Petrie et al., 2015; Barnes et al., 2008; ). With regarding to these subjects, ACT was selected as the model pollutant in this research to examine the effectiveness of the $\mathrm{SnO}_{2}$ nanocomposites prepared by the sol-gel method to remove pharmaceutical compounds from aquatic solutions.

Taken together, the main objectives of this study were: (1) to synthesize several preparations of $\mathrm{SnO}_{2}$ nanocomposites by employing a novel sol-gel method under different synthesis conditions, (2) to evaluate the efficacy of obtained $\mathrm{SnO}_{2}$ preparations as potential catalysts for the COP in removing ACT from highly polluted aquatic environments. It should be mentioned that, only a few studies have investigated the application of $\mathrm{SnO}_{2}$-based COP for catalytic oxidation of water pollutants such as carbamazepine (Begum and Ahmaruzzaman, 2018) and decolonization molasses fermentation (Zeng et al., 2009) of wastewater, but no study has evaluated its effect in removing PCs from aqueous solutions. Of note, the degradation and mineralization ratio of ACT as well as its removal kinetics with different $\mathrm{SnO}_{2}$ preparations in the COP were also examined and compared with those results obtained in the SOP and adsorption onto catalysts. Moreover, the characteristics of the prepared catalysts including specific surface area, shape, crystallinity, particle size, pore volume, surface functional groups and active sites, morphological and structural properties as well as ACT mechanism of degradation via the catalytic ozonation process were investigated in this study.

\section{Materials and methods}

\subsection{Chemicals}

The chemicals including Tin tetrachloride $\left(\mathrm{SnCl}_{4}\right)$, Tin (II) Sulfate $\left(\mathrm{SnSO}_{4}\right)$, Cetyltrimethylammonium bromide (CTAB), Sodium dodecyl sulfate (SDS), $\mathrm{NaOH}, \mathrm{NH}_{4} \mathrm{OH}$ ( $25 \%$ solution in water), Acetaminophen (ACT), and ethanol were of analytical grade and all were purchased from Sigma-Aldrich Corporation (St. Louis, MO, USA). Double distilled water was used as the solvent in all the experiments. The mobile phase in HPLC analysis was a mixture of analytical grade Acetonitrile and ultrapure water.

\subsection{Catalyst preparation}

As previously mentioned, the sol-gel method employed in this study to synthesize $\mathrm{SnO}_{2}$ nanocomposite. To this end, several parameters including two types of tin sources $\left(\mathrm{SnCl}_{4}\right.$ and $\left.\mathrm{SnSO}_{4}\right)$, presence or absence of capping agents (SDS and CTAB), type of alkaline and/or gelation substances $\left(\mathrm{NaOH}, \mathrm{NH}_{4} \mathrm{OH}\right)$, and calcination temperatures $\left(450-650{ }^{\circ} \mathrm{C}\right.$ ) were considered to synthesize different $\mathrm{SnO}_{2}$ preparations. Then, these catalysts were examined for the catalytic ozonation of ACT under different conditions given in Table 1.

Briefly, in each run, $1 \mathrm{~g}$ of tin source was dissolved in $50 \mathrm{~mL}$ double distilled water and stirred magnetically at $100 \mathrm{rpm}$ for $30 \mathrm{~min}$ at room temperature. Afterwards, $1 \mathrm{~g}$ capping agent (according to Table 1) was added to the obtained mixture and stirred for another $2 \mathrm{~h}$. Thereafter, the solution $\mathrm{pH}$ was raised to 9 with the addition of an alkaline agent $\left(\mathrm{NaOH} / \mathrm{NH}_{4} \mathrm{OH}\right)$, and stirred at $30 \mathrm{rpm}$ for further $12 \mathrm{~h}$ until a yellow/ white gel was obtained. To concentrate the preparation, the obtained gel was centrifuged for $5 \mathrm{~min}$ at $5000 \mathrm{rpm}$. Subsequently, the prepared gel was washed three times by the use of distilled water/ethanol mixture (50:50, v-v) to remove non-dissolved particles/ impurities from the 
Table 1

Different $\mathrm{SnO}_{2}$ nanoparticles and preparation conditions.

\begin{tabular}{|c|c|c|c|c|}
\hline $\begin{array}{l}\text { Code of } \\
\mathrm{SnO}_{2}\end{array}$ & $\begin{array}{l}\text { Tin } \\
\text { Source }\end{array}$ & $\begin{array}{l}\text { Gelation } \\
\text { agent }\end{array}$ & $\begin{array}{l}\text { Capping } \\
\text { agents }\end{array}$ & $\begin{array}{l}\text { Calcination } \\
\text { temperature }\left({ }^{\circ} \mathrm{C}\right)\end{array}$ \\
\hline SnNa-450 & $\mathrm{SnCl}_{4}$ & $\mathrm{NaOH}(6 \mathrm{M})$ & - & 450 \\
\hline SnNa-550 & $\mathrm{SnCl}_{4}$ & $\mathrm{NaOH}(6 \mathrm{M})$ & - & 550 \\
\hline SnNa-650 & $\mathrm{SnCl}_{4}$ & $\begin{array}{l}\mathrm{NaOH} \\
(6 \mathrm{M})\end{array}$ & - & 650 \\
\hline SnNH-450 & $\mathrm{SnCl}_{4}$ & $\begin{array}{l}\mathrm{NH}_{4} \mathrm{OH} \\
(25 \%)\end{array}$ & - & 450 \\
\hline SnNH-550 & $\mathrm{SnCl}_{4}$ & $\begin{array}{l}\mathrm{NH}_{4} \mathrm{OH} \\
(25 \%)\end{array}$ & - & 550 \\
\hline SnNH-650 & $\mathrm{SnCl}_{4}$ & $\begin{array}{l}\mathrm{NH}_{4} \mathrm{OH} \\
(25 \%)\end{array}$ & - & 650 \\
\hline SnNaS-450 & $\mathrm{SnCl}_{4}$ & $\mathrm{NaOH}(6 \mathrm{M})$ & SDS & 450 \\
\hline SnNaS-550 & $\mathrm{SnCl}_{4}$ & $\mathrm{NaOH}(6 \mathrm{M})$ & SDS & 550 \\
\hline SnNaS-650 & $\mathrm{SnCl}_{4}$ & $\begin{array}{l}\mathrm{NaOH} \\
(6 \mathrm{M})\end{array}$ & SDS & 650 \\
\hline SnNaC-450 & $\mathrm{SnCl}_{4}$ & $\mathrm{NaOH}(6 \mathrm{M})$ & СТАВ & 450 \\
\hline SnNaC-550 & $\mathrm{SnCl}_{4}$ & $\mathrm{NaOH}(6 \mathrm{M})$ & CTAB & 550 \\
\hline SnNaC-650 & $\mathrm{SnCl}_{4}$ & $\begin{array}{l}\mathrm{NaOH} \\
(6 \mathrm{M})\end{array}$ & CTAB & 650 \\
\hline $\begin{array}{c}\text { SnNHS- } \\
450\end{array}$ & $\mathrm{SnCl}_{4}$ & $\begin{array}{l}\mathrm{NH}_{4} \mathrm{OH} \\
(25 \%)\end{array}$ & SDS & 450 \\
\hline $\begin{array}{c}\text { SnNHS- } \\
550\end{array}$ & $\mathrm{SnCl}_{4}$ & $\begin{array}{l}\mathrm{NH}_{4} \mathrm{OH} \\
(25 \%)\end{array}$ & SDS & 550 \\
\hline $\begin{array}{c}\text { SnNHS- } \\
650\end{array}$ & $\mathrm{SnCl}_{4}$ & $\begin{array}{l}\mathrm{NH}_{4} \mathrm{OH} \\
(25 \%)\end{array}$ & SDS & 650 \\
\hline $\begin{array}{c}\text { SnNHC- } \\
450\end{array}$ & $\mathrm{SnCl}_{4}$ & $\begin{array}{l}\mathrm{NH}_{4} \mathrm{OH} \\
(25 \%)\end{array}$ & CTAB & 450 \\
\hline $\begin{array}{c}\text { SnNHC- } \\
550\end{array}$ & $\mathrm{SnCl}_{4}$ & $\begin{array}{l}\mathrm{NH}_{4} \mathrm{OH} \\
(25 \%)\end{array}$ & СТАВ & 550 \\
\hline $\begin{array}{c}\text { SnNHC- } \\
650\end{array}$ & $\mathrm{SnCl}_{4}$ & $\begin{array}{l}\mathrm{NH}_{4} \mathrm{OH} \\
(25 \%)\end{array}$ & СТАВ & 650 \\
\hline SONa-550 & $\mathrm{SnSO}_{4}$ & $\mathrm{NaOH}(6 \mathrm{M})$ & - & 550 \\
\hline SONH-550 & $\mathrm{SnSO}_{4}$ & $\begin{array}{l}\mathrm{NH}_{4} \mathrm{OH} \\
(25 \%)\end{array}$ & - & 550 \\
\hline SONaS-550 & $\mathrm{SnSO}_{4}$ & $\mathrm{NaOH}(6 \mathrm{M})$ & SDS & 550 \\
\hline $\begin{array}{c}\text { SONHS- } \\
550\end{array}$ & $\mathrm{SnSO}_{4}$ & $\begin{array}{l}\mathrm{NH}_{4} \mathrm{OH} \\
(25 \%)\end{array}$ & SDS & 550 \\
\hline $\begin{array}{c}\text { SONaC- } \\
550\end{array}$ & $\mathrm{SnSO}_{4}$ & $\mathrm{NaOH}(6 \mathrm{M})$ & СТАВ & 550 \\
\hline $\begin{array}{l}\text { SONHC- } \\
550\end{array}$ & $\mathrm{SnSO}_{4}$ & $\begin{array}{l}\mathrm{NH}_{4} \mathrm{OH} \\
(25 \%)\end{array}$ & СТАВ & 550 \\
\hline
\end{tabular}

preparation. At the end, the gel was dried in an oven under $80{ }^{\circ} \mathrm{C}$ for $24 \mathrm{~h}$. Ultimately, the dried gel was powdered by Laboratory Porcelain Mortar with Pestle and then calcined by raising the temperature with 4 ${ }^{\circ} \mathrm{C} \min ^{-1}$ to the predetermined level $\left(450-650^{\circ} \mathrm{C}\right)$ under air atmosphere.

\section{3. $\mathrm{COP}$ experiments and catalytic activity of prepared $\mathrm{SnO}_{2}$ catalysts}

To examine the maximum catalytic activity of the synthesized $\mathrm{SnO}_{2}$ nanocomposites and to select the optimized preparation of the catalysts, the removal efficiency of ACT in the COP and SOP experiments and adsorption onto $\mathrm{SnO}_{2}$ was calculated according to Eq. (1).

$$
\begin{aligned}
\text { Catalytic activity }(\%) & =\text { ACT degradation in } \mathrm{COP}-(\text { ACT degradation in SOP } \\
& \left.+ \text { ACT adsorption onto } \mathrm{SnO}_{2}\right)
\end{aligned}
$$

Since the ACT degradation in SOP and ACT adsorption onto the catalyst are the same for all the experiments, thus to find the precise catalytic activity of each catalyst, these values must be subtracted from the value of ACT degradation in COP. Accordingly, based on the Eq. (1), the highest catalytic activity was attributed to the $\mathrm{SnO}_{2}$ preparation which had higher ACT degradation in COP by subtracting ACT degradation in SOP and ACT adsorption onto catalyst.

As shown in Fig. S1, a bench scale reactor was used to perform the experiments in batch mode. The pilot was consisted of a cylindrical Pyrex reactor with the total volume of $250 \mathrm{~mL}$, a pure oxygen supply, an ozone generator, a catalytic ozone destructor and tubes, and fitting and valves. In order to improve the distribution of the ozone-containing gas stream entering the Pyrex-reactor, a sintered glass diffuser was embedded inside the reactor at the distance of $2 \mathrm{~cm}$ above the bottom the reactor (both in the SOP and COP experiments). To obtain a thoroughly mixed suspension, the reactor content was magnetically stirred at $100 \mathrm{rpm}$. Pure oxygen was fed into a ozone generator (HC4, Xylem Co. WEDECO brand, Netherlands), which produced ozone with a capacity of $0.4-4 \mathrm{~g} \mathrm{O}_{3} / \mathrm{h}$. The ozone dose was kept constant $1.6 \mathrm{mg} \mathrm{O} /$ min during the COP and SOP experiments by adjusting the inlet ozone at $0.2 \mathrm{~L} / \mathrm{min}$ and $8 \mathrm{mg} / \mathrm{L}$ for flow rate and concentration, respectively. The desired dosages of ozone was obtained by regulating the rate of airflow passing through the generator. The concentration of ozone in the feed gas and off gas streams was measured by an ozone analyzer (BMT 964 C, RMT MESSTECHIK, WEDECO company, BERLIN, Germany).

For each $\mathrm{COP}$ experiment, $1.30 \mathrm{~g} / \mathrm{L} \mathrm{SnO}{ }_{2}$ powder was added to the reaction solution and the ozone generator was switched on for a predetermined time period (2, 5, 10, 15, 20 and $30 \mathrm{~min})$. The concentration of $1.30 \mathrm{~g} / \mathrm{L} \mathrm{SnO}{ }_{2}$ was chosen according to similar studies of AOPs with $\mathrm{SnO}_{2}$ as catalyst (Begum and Ahmaruzzaman, 2018; Zeng et al., 2009) and pre-test results. The same procedure was applied for the adsorption and SOP experiments except that the ozone generator was switched off in the adsorption tests and no catalyst was used in the SOP. During the experiments, the reactor content was stirred magnetically at $100 \mathrm{rpm}$ to maintain a well-mixed suspension. The suspension in the reactor was filtered at the end of adsorption and COP experiments using a syringe filter (Macherey-Nagel GmbH \& Co.KG Germany) with a pore size of $0.45 \mu \mathrm{m}$ and the filtrate was analysed for the remaining ACT concentration. More details about COP experiments can be found in the SI (Text S1).

\subsection{Catalyst characterization}

The characteristics of some catalysts preparations (7 of 24 prepared catalysts) were studied based on their surface morphology, texture as well as particle size distribution with the use of different techniques including XRD, XRF, SEM, EDX, TEM, BET, BJH and FTIR. Details of the experimental techniques utilized for characterization of the selected synthesized catalysts are presented in Table S1. The selection of catalysts to characterize their physico-chemical properties was based on the results obtained from COP experiments, in which the optimized $\mathrm{SnO}_{2}$ and the catalyst with lowest efficiency were determined by considering various synthetic parameters including Tin source, type of gelation and capping agents as well as calcination temperature.

\subsection{Performance indices and analytical methods}

The concentrations of ACT in the filtered solution underwent SOP, COP and adsorption experiments were measured using a Phenomenex HPLC (Kinetex Core-shell C18 column; $2.6 \mu \mathrm{m}, 4.6 \times 100 \mathrm{~mm}$ ) equipped with a UV detector $(215 \mathrm{~nm})$. Details of the HPLC experiments, along with the procedures employed for ACT degradation and mineralization are presented in SI (Text S2). The degradation efficiency was measured based on ACT removal, while mineralization efficiency obtained through the TOC analysis.

The ACT degradation and mineralization kinetics for both SOP and $\mathrm{COP}$ processes were determined using pseudo-first-order ( $\mathrm{PFO}$ ) reaction model, as described by Eqs. (2) and (3) (Moussavi et al., 2012):

$\ln \left(\frac{C_{t}}{C_{0}}\right)=-k_{\text {obs }} t$

$r_{1}=-\frac{d C}{d t}=k_{o b s} \mathrm{C}$

In the above equations $C_{0}$ and $C_{t}$ refers to the initial ACT concentration and its amount after reaction for time $t$, respectively, and $\mathrm{k}_{\mathrm{obs}}$ is the PFO constant. Moreover, $r_{1}$ demonstrates the degradation rate of 
ACT.

A liquid chromatography/mass spectrometry (LC/MS) was also used to examine the intermediate products generated during degradation of ACT in the COP. Details about the LC/MS performance are presented in SI (Text S3).

The nitrate concentration was measured by using a spectrophotometer (UV/Vis, Perkin-Elmer 550 SE, USA) according to the water and wastewater Standard methods (APHA, Standard Methods for the Examination of Water and Wastewater, 20th edn, American Public Health Association, American Water Works Association and Water Environment Federation, (1998) 1998.).

\subsection{Catalyst Reusability}

From a practical viewpoint, the reusability of catalysts is an important feature that determines the cost-effectiveness of the process. In this regard, the catalytic performance as well as the reusability of synthesized $\mathrm{SnO}_{2}$ nanoparticles was evaluated in $\mathrm{COP}$ through three successive experiments. In order to evaluate the reusability of the catalyst, $1.3 \mathrm{~g} / \mathrm{L}$ of $\mathrm{SnO}_{2}$ was used at $\mathrm{pH} 7$, an ACT concentration of $50 \mathrm{mg} / \mathrm{L}$, an $\mathrm{O}_{3}$ dosage of $1.6 \mathrm{mg} \mathrm{O}_{3} / \mathrm{min}$, and at reaction time of $30 \mathrm{~min}$. For this, the previously prepared catalyst suspension was centrifuged at $5000 \mathrm{rpm}$ for $5 \mathrm{~min}$. The c catalyst was collected and washed for several times with distilled water in order to remove any impurity and then dried for $1 \mathrm{~h}$ at $105{ }^{\circ} \mathrm{C}$ in a hot air oven, and used for the next COP experiment at the same conditions without any modification.

\section{Results and discussion}

\subsection{Kinetics and catalytic activity of the synthesized nanoparticles}

The degradation kinetics of ACT using different preparations of $\mathrm{SnO}_{2}$ composite were examined for both SOP and COP processes and are summarized in Table 2 . We found that under the experimental conditions only ${ }^{<} \%$ of ACT removal was occurred through its adsorption onto the synthesized nanocatalysts. Moreover, at a contact time of $10 \mathrm{~min}$, SOP was responsible for $30.55 \%$ ACT degradation. These findings indicate that the addition of $\mathrm{SnO}_{2}$ nanocomposite to ozonation process (COP) could efficiently enhance ACT degradation compared to individual ozonation or adsorption onto catalyst. Since the removal of ACT by sole catalyst was negligible, hence we did not perform kinetic studies for the adsorption of ACT onto catalysts.

According to the results presented in Table 2, the higher degradation of ACT was achieved when the catalysts were prepared with $\mathrm{SnCl}_{4}$, as tin source, compared to $\mathrm{SnSO}_{4}$. For example, under the same conditions, the degradation rate of ACT in the COP with SnNaC-550 ( $\mathrm{r}_{\mathrm{COP}}$ - SnNaC-550 $=7.805 \mathrm{mg} \mathrm{ACT} / \mathrm{L}$. min) was about 2.5 times greater than that rate found for SONaC-550 ( $\mathrm{r}_{\mathrm{COP}}$ SONaC-550 $=3.115 \mathrm{mg}$ ACT $/ \mathrm{L}$. min). Moreover, regardless of the tin source, those catalysts which were prepared by $\mathrm{NaOH}$ as gelatine agent exhibited higher $\mathrm{r}_{\mathrm{COP}}$ than the catalysts (with the same tin source) prepared by $\mathrm{NH}_{4} \mathrm{OH}$. As shown in Table 2, ACT degradation rate was about 1.8 times higher for the COP with SnNaS550 as catalyst $\left(\mathrm{r}_{\mathrm{COP}}=6.895 \mathrm{mg}\right.$ ACT $/ \mathrm{L}$. $\mathrm{min}$ ) compared to SnNHS550 ( $\mathrm{r}_{\mathrm{COP}}=3.83 \mathrm{mg}$ ACT $/$ L. $\left.\mathrm{min}\right)$.

Furthermore, according to Table 2, it is obvious that the use of capping agent has also influenced the catalytic performance of $\mathrm{SnO}_{2}$ nanoparticles in removing ACT. According to the results a superior catalytic activity was observed for those catalysts capped with a capping agent (CTAB and/or SDS), compared to those preparations were not capped. This phenomenon was more pronounced for the $\mathrm{SnO}_{2}$ preparations capped with CTAB compared to SDS (SnNaC-550 > SnNaS$550>$ SnNa-550). Our results are in line with the findings of Begum et al. (Begum and Ahmaruzzaman, 2018) who showed higher degradation capacity for $\mathrm{CTAB}$ capped $\mathrm{SnO}_{2}$ nanoparticles in removing carbamazepine from aqueous solutions compared to those $\mathrm{SnO}_{2}$ nanoparticles capped with SDS.
Table 2

Degradation kinetics of ACT in the COP and SOP experiments.

\begin{tabular}{|c|c|c|c|c|c|}
\hline $\begin{array}{l}\text { Type of } \\
\text { catalysts }\end{array}$ & $\begin{array}{l}\text { Maximum ACT } \\
\text { removal percentage } \\
(10 \mathrm{~min})\end{array}$ & $\mathrm{R}^{2}$ & $\begin{array}{l}\mathrm{k}_{\mathrm{obs}}(1 / \\
\mathrm{min})\end{array}$ & $\begin{array}{l}\mathrm{r}(\mathrm{mg} \\
\mathrm{ACT} / \mathrm{L} . \\
\min )\end{array}$ & $\begin{array}{l}\mathrm{r}_{\mathrm{COP} /} \\
\text { sOP }\end{array}$ \\
\hline $\begin{array}{c}\text { SnNaC- } \\
550\end{array}$ & 95.4 & 0.5306 & 0.1561 & 7.805 & 2.90 \\
\hline $\begin{array}{c}\text { SnNaC- } \\
450\end{array}$ & 94.9 & 0.5456 & 0.1506 & 7.53 & 2.80 \\
\hline SnNaS-550 & 90.6 & 0.8606 & 0.1379 & 6.895 & 2.56 \\
\hline SnNa-550 & 89.3 & 0.5277 & 0.1203 & 6.015 & 2.24 \\
\hline $\begin{array}{c}\text { SnNaC- } \\
650\end{array}$ & 84.1 & 0.595 & 0.1167 & 5.835 & 2.17 \\
\hline SnNa-450 & 82.9 & 0.7326 & 0.1084 & 5.42 & 2.01 \\
\hline SnNa-650 & 82.4 & 0.8046 & 0.0954 & 4.77 & 1.77 \\
\hline SnNaS-650 & 73.9 & 0,6252 & 0.0914 & 4.57 & 1.70 \\
\hline $\begin{array}{c}\text { SnNHS- } \\
450\end{array}$ & 59.0 & 0.9258 & 0.0885 & 4.425 & 1.64 \\
\hline $\begin{array}{c}\text { SONaS- } \\
550\end{array}$ & 58.2 & 0.9559 & 0.0785 & 3.925 & 1.46 \\
\hline $\begin{array}{c}\text { SnNHS- } \\
650\end{array}$ & 55.8 & 0.9563 & 0.077 & 3.85 & 1.43 \\
\hline $\begin{array}{c}\text { SnNHS- } \\
550\end{array}$ & 52.5 & 0.955 & 0.0766 & 3.83 & 1.42 \\
\hline SnNaS-450 & 49.4 & 0.9967 & 0.0741 & 3.705 & 1.38 \\
\hline SnNH-450 & 49.0 & 0.9971 & 0.0732 & 3.66 & 1.36 \\
\hline $\begin{array}{c}\text { SnNHC- } \\
550\end{array}$ & 46.0 & 0.9982 & 0.0678 & 3.39 & 1.26 \\
\hline $\begin{array}{c}\text { SONHS- } \\
550\end{array}$ & 41.0 & 0.9912 & 0.064 & 3.2 & 1.19 \\
\hline SnNH-650 & 38.9 & 0.9872 & 0.0636 & 3.18 & 1.18 \\
\hline $\begin{array}{c}\text { SnNHC- } \\
450\end{array}$ & 37.6 & 0.893 & 0.063 & 3.15 & 1.17 \\
\hline SnNH-550 & 36.9 & 0.9761 & 0.0625 & 3.125 & 1.16 \\
\hline $\begin{array}{l}\text { SONaC- } \\
550\end{array}$ & 35.1 & 0.9494 & 0.0623 & 3.115 & 1.16 \\
\hline $\begin{array}{c}\text { SONHC- } \\
550\end{array}$ & 34.0 & 0.9593 & 0.062 & 3.1 & 1.15 \\
\hline $\begin{array}{c}\text { SnNHC- } \\
650\end{array}$ & 33.1 & 0.9499 & 0.0618 & 3.09 & 1.15 \\
\hline SONa-550 & 32.9 & 0.9533 & 0.0616 & 3.08 & 1.14 \\
\hline SONH-550 & 23.4 & 0.9228 & 0.0614 & 3.07 & 1.14 \\
\hline Process & $\begin{array}{l}\text { Maximum ACT } \\
\text { removal percentage } \\
(10 \mathrm{~min})\end{array}$ & $\mathrm{R}^{2}$ & $\begin{array}{l}\mathrm{k}_{\mathrm{obs}}(1 / \\
\mathrm{min})\end{array}$ & $\begin{array}{l}\mathrm{r}(\mathrm{mg} \\
\mathrm{ACT} / \mathrm{L} . \\
\min )\end{array}$ & $\begin{array}{l}\mathrm{r}_{\mathrm{COP} /} \\
\text { sOP }\end{array}$ \\
\hline SOP & 30.55 & 0.9366 & 0.0538 & 2.69 & - \\
\hline
\end{tabular}

Calcination temperature is another parameter has been shown can affect the performance of nanocatalysts (Zhong et al., 2012). In this regards, we found that (Table 2), the catalysts those prepared at a calcination temperature of $550{ }^{\circ} \mathrm{C}$ had higher $\mathrm{r}_{\mathrm{COP}}$ than the catalysts were prepared at other calcination temperatures. The trend for catalysts $\mathrm{r}_{\mathrm{COP}}$ based on the calcination temperature were SnNaC-550 $>$ SnNaC$450>$ SnNaC-650 and/or SnNaS-550 > SnNaS-650 > SnNaS-450.

Taken together, we observed higher efficiency in the ACT degradation for the catalysts prepared with $\mathrm{SnCl}_{4}$ as tin source, $\mathrm{NaOH}$ as alkaline agent, $\mathrm{CTAB}$ as capping agent and the calcination temperature of $550{ }^{\circ} \mathrm{C}$ compared to those preparations obtained at the other conditions. Therefore, according to these preliminary results, $\mathrm{SnNaC}-550$ and SONH-550 were the catalysts which had higher and lower $r_{C O P}$, respectively.

In the next experiments, the degradation and mineralization rates of ACT in the integrated $\mathrm{SnO}_{2}$-based $\mathrm{COP}$ were examined to find the optimum reaction time and the obtained results were compared with those values in the sole ozonation process (SOP).

The mineralization kinetics of ACT in the COP experiments conducted by SnNaC-550, SONH-550 were compared to the results obtained from SOP and are presented in Table 3. These results showed that, the ACT mineralization rate in the SOP, SONH-550-based COP, and SnNaC550-based COP was 0.78, 0.93 and $3.74 \mathrm{mg}$ ACT /L. min, respectively. Accordingly, a $\mathrm{r}_{\mathrm{COP} / \mathrm{SOP}}$ ratio of 4.7 was obtained for $\mathrm{SnNaC}-550$, as the catalyst with the optimum performance, while the $\mathrm{r}_{\mathrm{COP} / \mathrm{SOP}}$ ratio was 
Table 3

Kinetics of ACT mineralization in the COP experiments based on SnNaC-550, SONH-550 and in the SOP experiments.

\begin{tabular}{llllll}
\hline $\begin{array}{l}\text { Type of } \\
\text { process }\end{array}$ & $\begin{array}{l}\text { Maximum ACT } \\
\text { removal percentage } \\
(10 \text { min) }\end{array}$ & $\mathrm{R}^{2}$ & $\begin{array}{l}\mathrm{k}_{\text {obs }}(1 / \\
\mathrm{min})\end{array}$ & $\begin{array}{l}\mathrm{r}(\mathrm{mg} \\
\mathrm{ACT} / \mathrm{L} . \\
\mathrm{min})\end{array}$ & $\begin{array}{l}\mathrm{r}_{\text {COP/ }} \\
\text { sOP }\end{array}$ \\
\hline $\begin{array}{l}\text { SnNaC-550- } \\
\text { based }\end{array}$ & 72.0 & 0.7105 & 0.0747 & 3.74 & 4.79 \\
$\begin{array}{c}\text { COP } \\
\begin{array}{c}\text { SONH-550- } \\
\text { based } \\
\text { COP }\end{array}\end{array}$ & 20.6 & 0.9328 & 0.0185 & 0.93 & 1.50 \\
SOP & 15.9 & 0.9748 & 0.0156 & 0.78 & - \\
\hline
\end{tabular}

calculated 1.5 for SONH-550, as the preparation with the least catalytic performance. These findings indicate that $\mathrm{SnO}_{2}$ catalysts prepared by the new sol-gel method have remarkable catalytic potential for the ACT degradation and mineralization.

As previously mentioned, in this step, the effect of reaction time on the performance of prepared catalysts in the COP was examined. To this end, the degradation and mineralization of ACT $(50 \mathrm{mg} / \mathrm{L})$ by $\mathrm{SnNaC}$ 550 (high performance catalyst) and SONH-550 (low performance catalyst) integrated with ozonation (COP) were examined at different reaction times and compared to those results obtained in SOP. As depicted in Fig. 1a, the efficiency of ACT degradation in the SOP was improved approximately from $5.3 \%$ to $61.2 \%$ by increasing the contact time from 2 to $20 \mathrm{~min}$, respectively. However, we observed that the degradation of ACT was considerably increased by $40.5 \%$ when $1.3 \mathrm{~g} / \mathrm{L}$ of SnNaC-550 was added into the ozonation process (COP) at the reaction time of $2 \mathrm{~min}$. As expected, the results obtained for SONH-550based COP (low performance catalyst) was somehow similar to the SOP results. In addition, the ACT degradation efficiency in the SnNaC550-based COP was increased from $40.5 \%$ to $95.4 \%$, by increasing the contact time from 2 to $10 \mathrm{~min}$. However, negligible improvement $(0.1 \%)$ was observed by further increasing the reaction time (up to $20 \mathrm{~min}$ ). Therefore, according to Eq. (1), the catalytic activity of SnNaC550-based COP was enhanced from $34.6 \%$ to a maximum of $64.8 \%$, when the reaction time increased from $2 \mathrm{~min}$ to $10 \mathrm{~min}$. The mineralization efficiency of ACT based on TOC reduction as a function of reaction time is shown in Fig. 1b. As it is obvious, the ACT mineralization in the SOP was increased from $4.6 \%$ to $34.7 \%$ by increasing the reaction time from 2 to $30 \mathrm{~min}$. A similar trend was also detected for the SONH550-based COP, demonstrating that SONH-550 cannot be considered as a capable catalyst for ACT degradation and mineralization. However, when SnNaC-550 used as catalyst in the COP, the ACT mineralization was improved from $32 \%$ to $84 \%$, by increasing the contact time from 2 to $30 \mathrm{~min}$. Furthermore, the catalytic potential of about $56 \%$ was attained for the mineralization of ACT by adding SnNaC-550 into the ozonation reactor at $10 \mathrm{~min}$ reaction time. Collectively, the results show that $\mathrm{SnNaC}-550$, as the optimized $\mathrm{SnO}_{2}$ nanoparticles, had a desirable catalytic performance in degradation and mineralization of ACT when added to the ozonation process. Additionally, since the maximum degradation and mineralization of ACT as well as the optimum performance of the COP was achieved at 10 min reaction time, the next COP experiments were set at this reaction time.
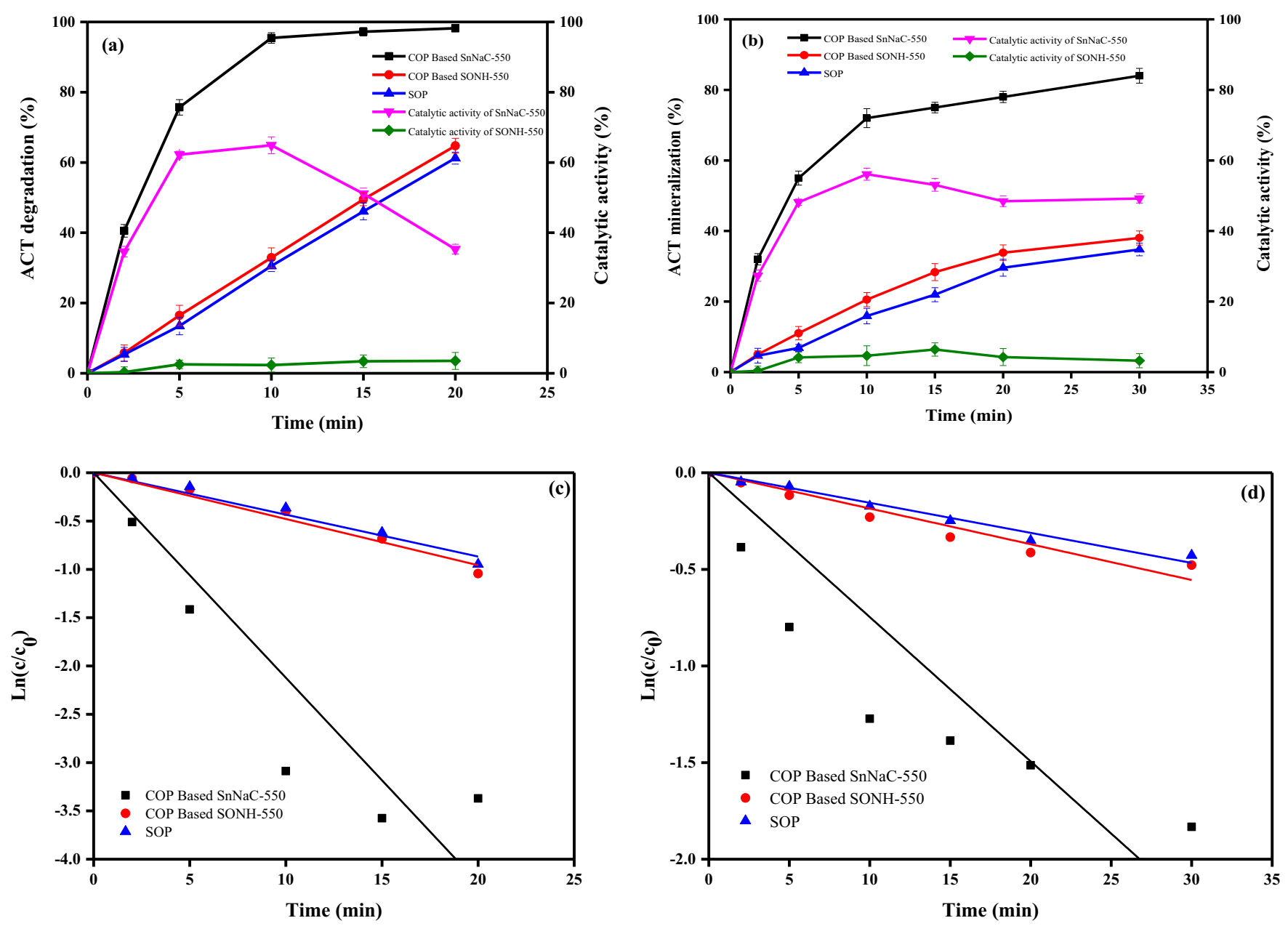

Fig. 1. ACT degradation (a) and mineralization (b) trend as a function of reaction time with the adjusted line equations for ACT degradation (c) and ACT mineralization (d) in the investigated processes (conditions: $\mathrm{pH}$ : 7; ACT concentration: $50 \mathrm{mg} / \mathrm{L}$; $\mathrm{SnO}_{2}$ dosage: $1.3 \mathrm{~g} / \mathrm{L}$ and $\mathrm{O}_{3}$ dosage: $1.6 \mathrm{mg} \mathrm{O}_{3} / \mathrm{min}_{\text {) }}$. 
As mentioned earlier, there are no previous studies which have investigated the effect of the integrated $\mathrm{SnO}_{2}$-based $\mathrm{COP}$ in the degradation of ACT. However, a broad spectrum of nanomaterials have been evaluated combined with the ozonation process for ACT removal from aquatic environments (Mashayekh-Salehi et al., 2017). Mashayekh et al. (Mashayekh-Salehi et al., 2017) showed that the SOP could remove ACT by the half (48\%) in a $50 \mathrm{mg} / \mathrm{L}$ solution, while the addition of $\mathrm{MgO}$ (adding $2 \mathrm{~g} / \mathrm{L} \mathrm{MgO}$ into the ozone reactor $\left(1.8 \mathrm{mg} \mathrm{O} \mathrm{O}_{3} / \mathrm{min}\right.$ )) considerably increased the ACT degradation from $14.8 \%$ to $99.9 \%$, by increasing the reaction time from 1 to $15 \mathrm{~min}$. Moreover, in the mentioned study (Mashayekh-Salehi et al., 2017), the maximum ACT mineralization for $\mathrm{O}_{3} / \mathrm{MgO}$ process was found $94 \%$ at a reaction time of $30 \mathrm{~min}$. In another study, Lin et al. (Lin et al., 2016) have studied the ACT degradation by the $\mathrm{UV} / \mathrm{TiO}_{2}$ process. According to their findings, the sole UV process removed only $12 \%$ of ACT, however when combined with $\mathrm{TiO}_{2}$ (UV/ $\mathrm{TiO}_{2}$ process), it removed $94 \%$ of the ACT. The $\mathrm{k}_{\mathrm{obs}}$ values of ACT degradation for sole $\mathrm{UV}$ and $\mathrm{UV} / \mathrm{TiO}_{2}$ processes were 0.009 and $0.043 \mathrm{~min}^{-1}$, respectively, while at the present work the $\mathrm{k}_{\mathrm{bos}}$ of $\mathrm{SnNaC}$ 550 -based COP was $0.353 \mathrm{~min}^{-1}$. There are also few studies have examined the catalytic removal of other PCs by $\mathrm{SnO}_{2}$ nanoparticles. In this regard, Begum and Ahmaruzzaman (Begum and Ahmaruzzaman, 2018) have investigated the catalytic degradation of 5 ppm carbamazepine by $\mathrm{SnO}_{2}$ as catalyst. They found that at a concentration of $0.6 \mathrm{~g} / \mathrm{L}$ of $\mathrm{SnO}_{2}$, solution $\mathrm{pH}$ of 5 and reaction time of $90 \mathrm{~min}$, the $\mathrm{SnO}_{2}$ nanoparticles capped with CTAB and SDS, were able to degrade $97 \%$ and $95 \%$ of carbamazepine, respectively when combined with UV irradiation (UV-C/SnO 2 process).

\subsection{Characteristics of the $\mathrm{SnO}_{2}$ nanoparticles}

\subsubsection{Crystalline phase identification}

The XRD patterns of the selected synthetized $\mathrm{SnO}_{2}$ nanoparticles are shown in Fig. 2. Accordingly, the peak patterns are relatively the same for all the $\mathrm{SnO}_{2}$ preparations which are also in accordance with the major peaks of $\mathrm{SnO}_{2}$ particles regarding to the Joint Committee on Powder Diffraction Standards (41-1445) (Zeng et al., 2009). As the results show, three clear peaks were observed at $2 \theta$ of $26.44^{\circ}, 33.8^{\circ}$ and $51.74^{\circ}$, which were attributed to the (110), (101) and (211) planes, respectively, and are related to the tetragonal rutile $\mathrm{SnO}_{2}$ crystal in its pure phase (Begum and Ahmaruzzaman, 2018). The other obvious peaks positioned at $2 \theta$ of $37.87^{\circ}, 54.61^{\circ}, 57.89^{\circ}, 61.9^{\circ}, 64.92^{\circ}, 65.91^{\circ}, 71.31^{\circ}$ and $78.69^{\circ}$ were related to (200), (220), (002), (310), (112), (301), (202) and (321) crystal planes, respectively, which are also fit well with the standard tetragonal structured $\mathrm{SnO}_{2}$ nanoparticles. Furthermore, when $\mathrm{SnSO}_{4}$ used as tin source (SONH-550), an orthorhombic $\mathrm{SnO}_{2}$ phase was observed at the peak position around $29.64^{\circ}(210)$. Based on

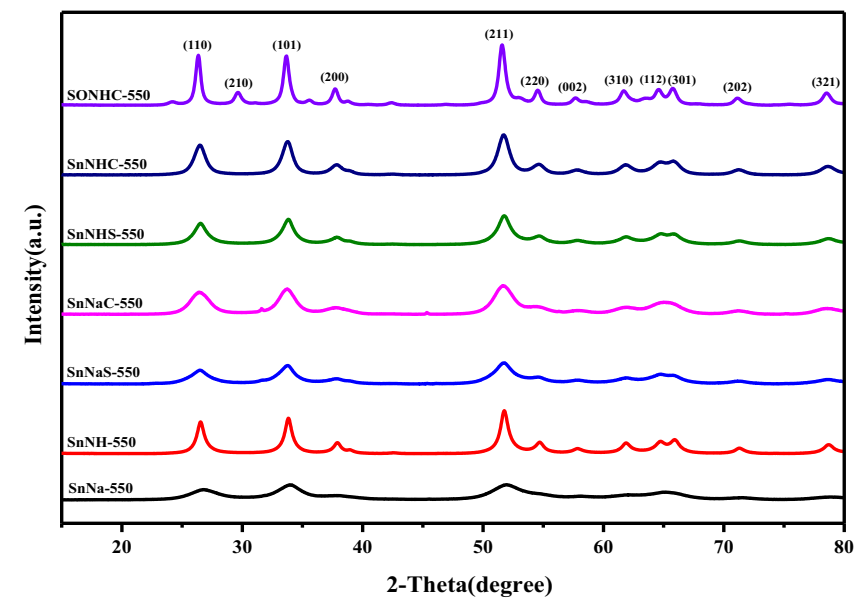

Fig. 2. The XRD patterns of the selected synthesized $\mathrm{SnO}_{2}$ nanoparticles. these XRD results, no peaks were found to be related to the impurities in any of the catalyst preparations.

The mean particle size (D) of the selected synthetized $\mathrm{SnO}_{2}$ nanoparticles was determined using the Debye-Scherrer equation (Begum and Ahmaruzzaman, 2018) according to the XRD data by the full width at half maximum (FWHM) of the diffraction peak:

$\mathrm{D}=\frac{K \lambda}{\beta \operatorname{Cos} \theta}$

Where $k$ is the shape coefficient (0.9), $\beta$ is the full width at half maximum (FWHM), $\lambda$ is the wavelength of $\operatorname{Co~}_{\alpha}$ radiation and $\theta$ is the reflection angel in degree $\left({ }^{\circ}\right)$. Based on the above equation, the average crystallite size of the prepared $\mathrm{SnO}_{2}$ nanoparticles was ranged from 3 to $13.2 \mathrm{~nm}$ as shown in Table S2. Our findings showed that the catalysts prepared by $\mathrm{NaOH}$ as alkaline agent ( $\mathrm{SnNaS}-550$ and/or SnNaC-550) had smaller crystalline size than those preparations obtained by $\mathrm{NH}_{4} \mathrm{OH}$ (SnNHC-550 and/or SnNH-550). Similarly, the use of $\mathrm{SnCl}_{4}$ as tin source in preparation of $\mathrm{SnO}_{2}$ nanoparticles resulted in smaller crystalline size compared to $\mathrm{SnSO}_{4}$. The average crystalline size of the synthetized $\mathrm{SnO}_{2}$ nanoparticles in the present work are close to those reported in the literature (Begum and Ahmaruzzaman, 2018; Zeng et al., 2009; Cao et al., 2013; Chang, 2019; Aziz et al., 2013). For example, the average crystalline size of $\mathrm{SnO}_{2}$ nanoparticles prepared with the precipitation methods for decolorization of molasses fermentation wastewater was obtained 7-11 nm (Zeng et al., 2009), and for degradation of carbamazepine from aqueous phase was reported 8-16 nm (Begum and Ahmaruzzaman, 2018).

\subsubsection{Structural and elemental composition}

The chemical composition of the synthesized catalysts was also investigated by the XRF technique and the results are given in Table S2. These results show that $\mathrm{SnO}_{2}(>93 \%)$ is the main compound in the all synthesized catalysts, which is in agreement with the XRD results. In the catalysts capped with SDS ( $\mathrm{SnNaS}-550$ and SnNHS-550), $\mathrm{SO}_{3}$ was also detected in the XRF spectra. The weight percentage of other chemical compounds including $\mathrm{SiO}_{2}, \mathrm{Nb}_{2} \mathrm{O}_{5}, \mathrm{Fe}_{2} \mathrm{O}_{3}, \mathrm{PbO}, \mathrm{Al}_{2} \mathrm{O}_{3}, \mathrm{NiO}, \mathrm{Cr}_{2} \mathrm{O}_{3}, \mathrm{P}_{2} \mathrm{O}_{5}$ and $\mathrm{K}_{2} \mathrm{O}$ in all synthesized catalysts was negligible (smaller than $1 \%$ ). In addition, the elemental concentrations in the synthesized catalysts was measured by EAX technique and reported in Fig. S2. According to EAX results, tin (Sn) and oxygen (O) were the main elements present in the $\mathrm{SnO}_{2}$ structure. Weight and atomic percentages of other detected elements including calcium (Ca), sulfur (S), sodium $(\mathrm{Na})$, chloride $(\mathrm{Cl})$ and silica ( $\mathrm{Si}$ ) were not considerable (smaller than 3\%). The elemental analysis showed the high purity of synthesized $\mathrm{SnO}_{2}$ nanoparticles and approved the XRD and XRF results.

\subsubsection{Pore properties and specific surface area}

$\mathrm{N}_{2}$ adsorption/desorption isotherms were used to determine total pore volume, average pore size and specific surface area of the selected synthetized $\mathrm{SnO}_{2}$ preparations (Fig. S3 and Table 4). Fig. S3 shows the pore size distributions of each selected catalyst. The attained isotherms could be considered as type IV based on the IUPAC classification and

Table 4

Pore properties and specific surface area of selected catalysts.

\begin{tabular}{llcl}
\hline Type of catalyst & $\mathrm{BET}^{\mathrm{a}}\left(\mathrm{m}^{2} / \mathrm{g}\right)$ & $\mathrm{d}_{\text {pore }}{ }^{\mathrm{b}}(\mathrm{nm})$ & $\mathrm{V}_{\text {tot }}{ }^{\mathrm{c}}\left(\mathrm{cm}^{3} / \mathrm{g}\right)$ \\
\hline SnNa-550 & 32 & 4.5 & 0.055 \\
SnNH-550 & 18 & 12.2 & 0.055 \\
SnNaS-550 & 38 & 5.9 & 0.086 \\
SnNaC-550 & 81 & 6.8 & 0.138 \\
SnNHS-550 & 21 & 10 & 0.053 \\
SnNHC-550 & 36 & 9.8 & 0.071 \\
SONH-550 & 9.9 & 15 & 0.035 \\
\hline
\end{tabular}

${ }^{a}$ BET specific surface area.

b Average pore size.

c Total pore volume. 


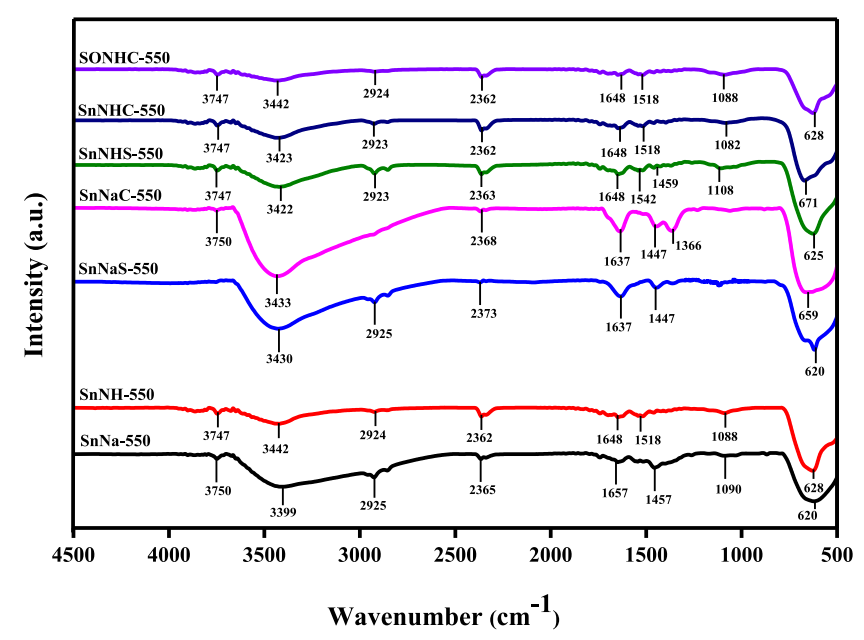

Fig. 3. The FTIR spectra of the selected synthesized $\mathrm{SnO}_{2}$ nanoparticles.

Brunauer-Demining-Demining-Teller (BDDT) model (Dimitrov et al., 2010). The isotherm loops of most selected catalysts (SnNaC-550, SnNH550 , SnNaS-550, SnNHS-550, SONH-550) fall in $p / p_{0}=0.50-0.90$ and exhibit a type $\mathrm{H} 1$ hysteresis indicating the porosity of the examined material which consists of agglomerates of somehow uniform particles with cylindrical mesoporous (Thommes, 2010). A very high $p / p_{0}=0.8-1$ was observed for the SnNHC-550 catalyst which indicates a H3 hysteresis loop that may be due to the existence of narrow slit-like mesoporous and macrospores (Mashayekh-Salehi et al., 2017). The $p / p_{0}=0.45-0.70$ for SnNa-550 catalyst, prepared without capping agent, exhibits a $\mathrm{H} 2$ type hysteresis loop defined as "ink bottle pores" which potentially might be due to the presence of some nonhomogeneous particles (Ravikovitch and Neimark, 2001).

According to the Table 4, among the prepared catalysts, SnNaC-550 had the highest specific surface area and large total pore volume based on the $\mathrm{r}_{\mathrm{COP}}$ : about $81 \mathrm{~m}^{2} / \mathrm{g}$ and $0.138 \mathrm{~cm}^{3} / \mathrm{g}$, respectively, with an average pore size of $6.8 \mathrm{~nm}$. However, SONH-550 (low performance catalyst) had the least specific surface area as well as low total pore volume indicated by the $r_{C O P}$, about $9.9 \mathrm{~m}^{2} / \mathrm{g}$ and $0.035 \mathrm{~cm}^{3} / \mathrm{g}$, respectively, with an average pore size of $15 \mathrm{~nm}$. These findings are in accordance with the catalytic activity experiments of these preparations. It has been demonstrated that the catalytic performance of a certain catalyst depends on its specific surface area (Pocostales et al., 2011; Lin et al., 2016). A high specific surface area can provide more available sites for generation of reaction species.

Based on the literature review, the specific surface area of the optimized catalyst (SnNaC-550) in the present study was somewhat larger than those catalysts have been reported previously (Dimitrov et al., 2010).

\subsubsection{Surface properties and particles size distribution}

The surface functional groups of the selected synthetized $\mathrm{SnO}_{2}$ nanocomposites are given in Fig. 3 as a typical FTIR spectrum. The FTIR spectra of the all selected $\mathrm{SnO}_{2}$ preparations are very similar. A strong bond at around $620-671 \mathrm{~cm}^{-1}$ was detected which can be attributed to the anti-symmetric vibrations of Sn-O-Sn band (Begum and Ahmaruzzaman, 2018; Begum et al., 2016). A broad bond at the $3399-3442 \mathrm{~cm}^{-1}$ and moderate bond at $1637-1657 \mathrm{~cm}^{-1}$ might be
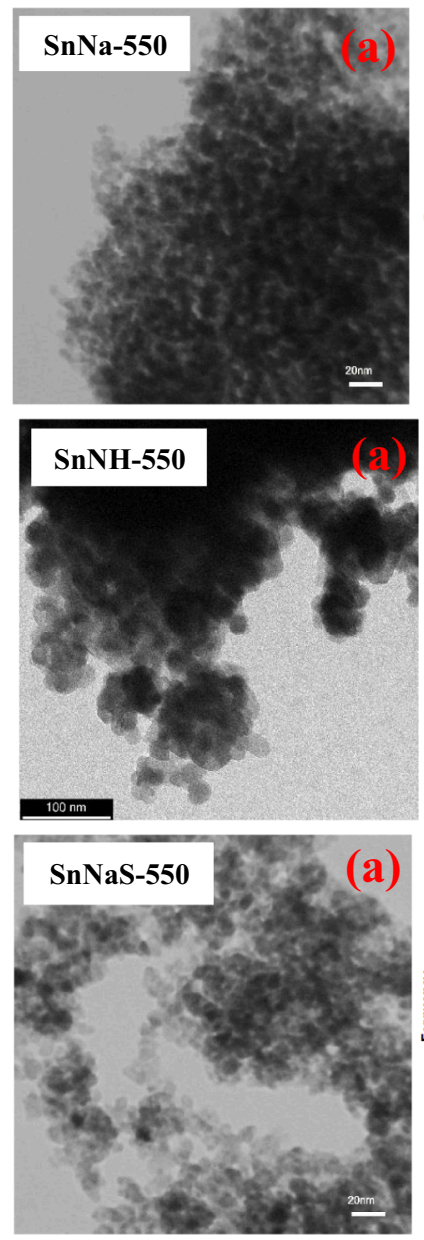
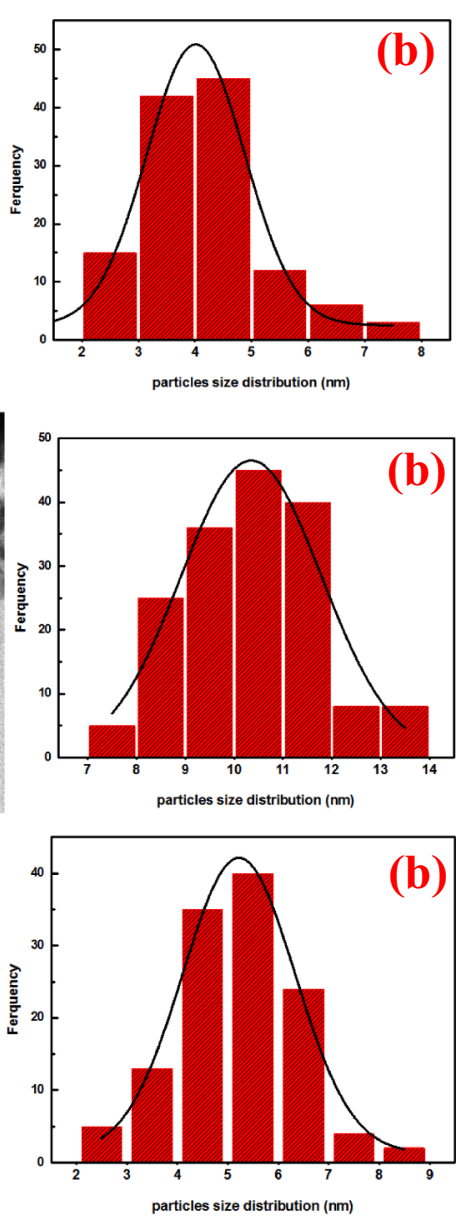
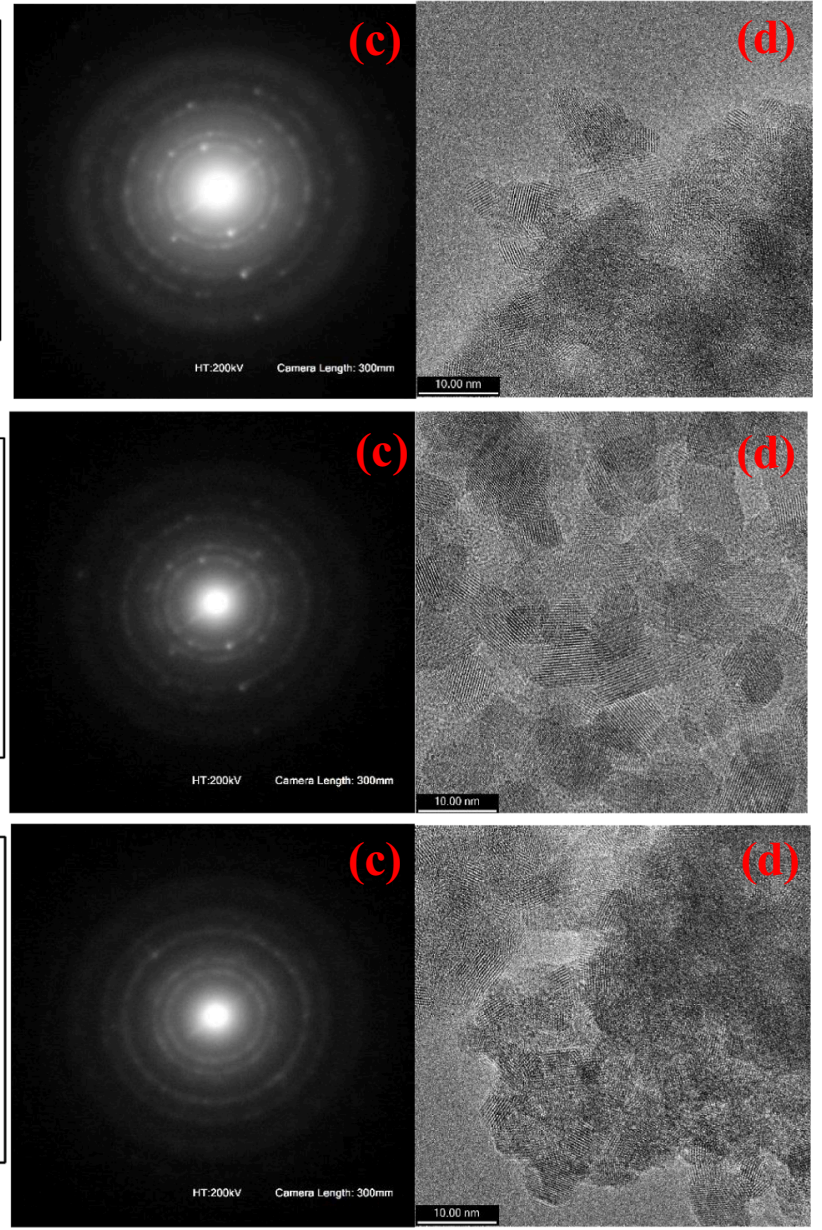

Fig. 4. TEM images (a), histogram of particle size distribution (b), SAED patterns (c) and HRTEM images (d) of the selected synthesized SnO ${ }_{2}$ nanoparticles . 

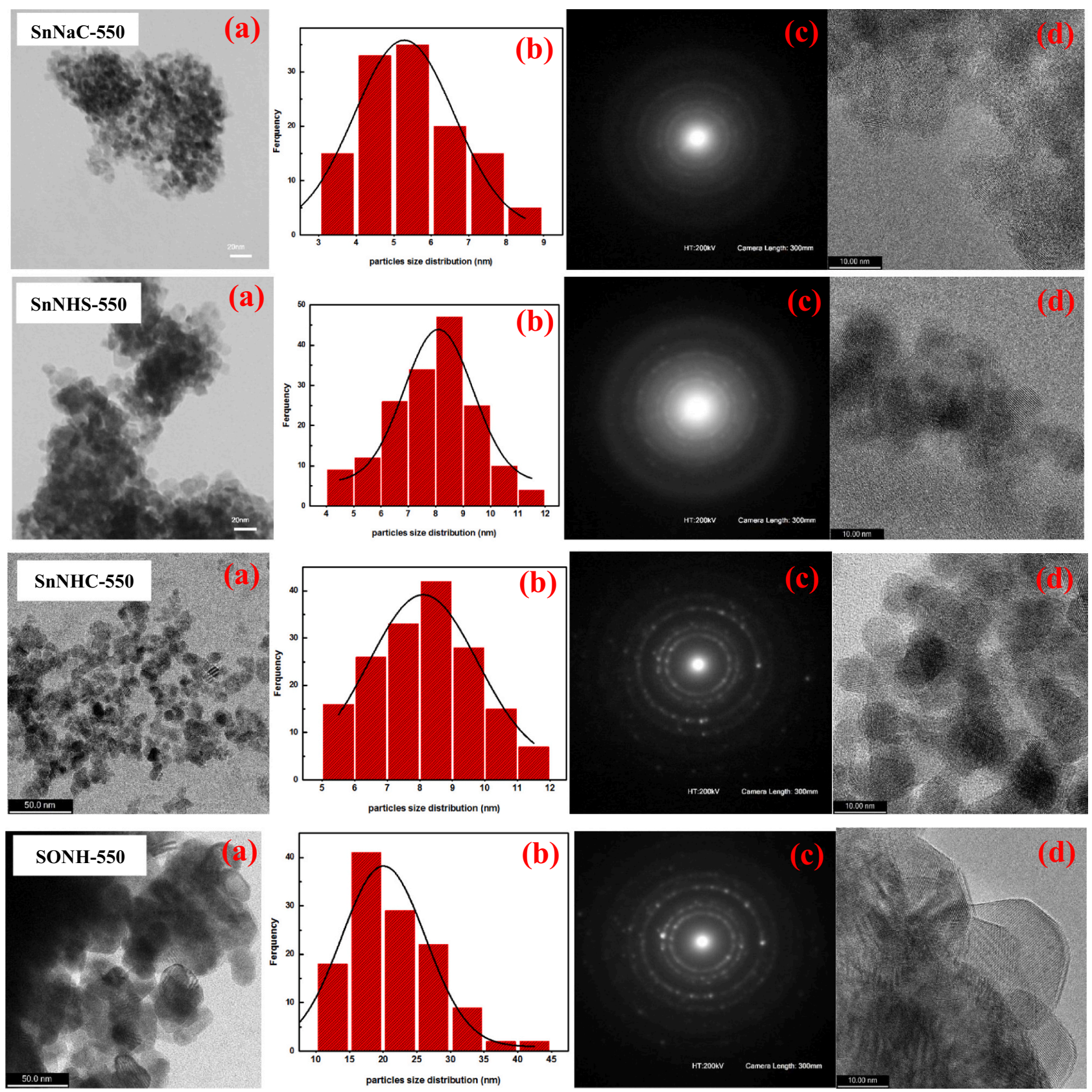

Fig. 4. (continued).

related to stretching vibration and bending vibration of hydroxyl groups $(-\mathrm{OH})$, respectively, which exists on the surface of $\mathrm{SnO}_{2}$ preparations due to the physical adsorption of $\mathrm{H}_{2} \mathrm{O}$ molecules (Begum and Ahmaruzzaman, 2018; Das and Roy, 2019; Jahnavi et al., 2019; Luque et al., 2020). The peak at 2923-2925 $\mathrm{cm}^{-1}$ detected in all selected $\mathrm{SnO}_{2}$ preparations can be related to the $\mathrm{C}-\mathrm{H}$ asymmetric stretching (Begum and Ahmaruzzaman, 2018). The surface morphology of the synthetized $\mathrm{SnO}_{2}$ preparations were also characterized using SEM (Fig. S4). From the SEM micrographs, it is evident that the $\mathrm{SnO}_{2}$ nano powder morphology is almost spherical in shape and forms agglomerates. The agglomeration might be resulted from strong hydrogen bonding in the gelatine step (Reddy et al., 2016). Furthermore, the observed similarity in shape and small particle size of SnNa-550, SnNaS-550 and SnNaC-550 catalysts compared to SnNH-550, SnNHS-550, SnNHC-550 and SONH-550 was assumed to be due to $\mathrm{NaOH}$ as alkaline agents.

To size distribution, morphological structure and microstructure of the selected $\mathrm{SnO}_{2}$ preparations, were scrutinized by using TEM, HRTEM images and SAED patterns. The TEM images (Fig. 4a) and the size distribution histograms (Fig. 4b) indicated that the particles are spherical in shape with sizes between 2 and $40 \mathrm{~nm}$. The average particle sizes for the SnNa-550, SnNH-550, SnNaS-550, SnNaC-550, SnNHS-550, SnNHC550 and SONH-550 catalysts were about 4.2, 10.5, 5.2, 5.5, 8.0, 8.3 and $21.9 \mathrm{~nm}$, respectively, as shown in Fig. 4b. These findings are a prove that the synthesized $\mathrm{SnO}_{2}$ preparations have nano-size structures. The average particle size of $\mathrm{SnO}_{2}$ nanomaterials prepared by other methods has been reported between 3 and $50 \mathrm{~nm}$ (Cao et al., 2013; Chang, 2019; Turgut and Sönmez, 2014; Gharibi et al., 2016)..

Diameter diffraction rings and lattice fringes were calculated from the SAED patterns (Fig. 4c) and HRTEM images (Fig. 4d). The bright concentric circles observed in the SAED patterns are indicative of polycrystalline nature of the analysed catalysts. According to the Dspacing value calculated based on the SAED patterns, all the plane (110), (101) and (211) obviously matched well with the lattice plane of rutile $\mathrm{SnO}_{2}$ (JCPDS 41-1445) (Begum and Ahmaruzzaman, 2018). Moreover, 


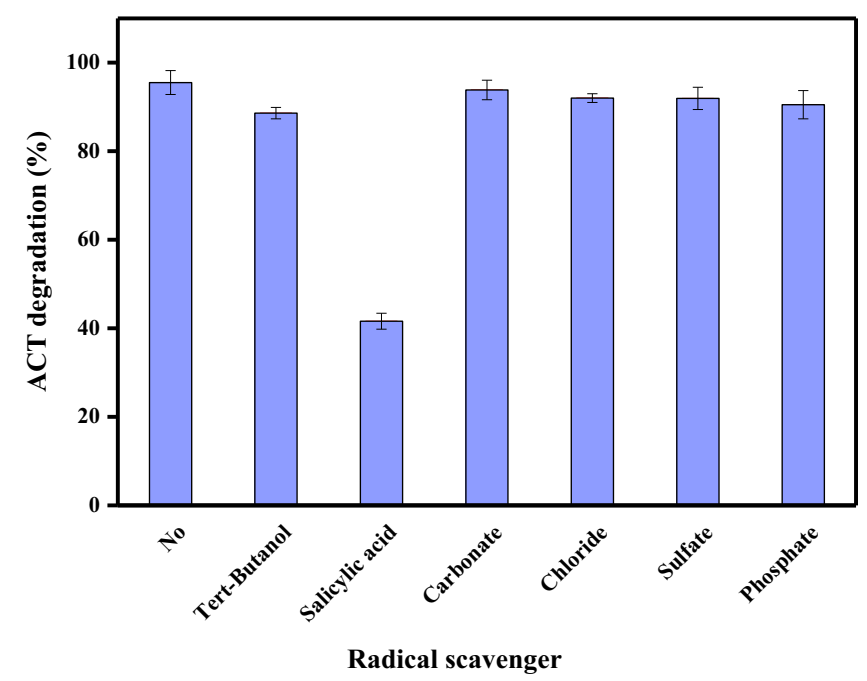

Fig. 5. Degradation efficiency of ACT in the COP with selected radical scavengers (conditions: pH: 7; ACT concentration: $50 \mathrm{mg} / \mathrm{L} ; \mathrm{SnO}_{2}(\mathrm{SnNaC}-550)$ dosage: $1.3 \mathrm{~g} / \mathrm{L}$ and $\mathrm{O}_{3}$ dosage: $1.6 \mathrm{mg} \mathrm{O} / \mathrm{min}$. The radical scavengers/inhibitors concentration in this study was $0.1 \mathrm{~g} / \mathrm{L}$, with an exception for the tertbutanol (4 g/L) and methanol (4 g/L)).

Fig. 4d depicts the HRTEM images of the selected synthetized $\mathrm{SnO}_{2}$ nanoparticles. Accordingly, the lattice spacings were calculated $0.33 \mathrm{~nm}, 0.26 \mathrm{~nm} 0.176 \mathrm{~nm}$, which matched to the (110), (101) and (211) planes of rutile $\mathrm{SnO}_{2}$.

\subsection{Mechanism of ACT degradation in COP}

In general, two main mechanisms underlie the ACT degradation in the heterogeneous COP (1) direct oxidation by ozone molecules, and (2) indirect oxidation by the reactive species produced from the interaction between dissolved ozone and catalyst surface. These possible reactions might be occurring simultaneously in the solution and/or on the surface of catalyst (Aramendía et al., 2003).

To examine which of the above mentioned mechanisms mainly involved in the ACT degradation in the $\mathrm{SnO}_{2}$-based COP, a set of experiments were done with and without several radical scavengers and inhibitors. The related ACT degradation efficiency is shown in Fig. 5. It should be mentioned that these experiments were carried out by the
SnNaC-550 catalyst, which was proven has the maximum catalytic activity. The initial solution $\mathrm{pH}$ was set at 7 , as the maximum catalytic activity of SnNaC-550 in removing ACT was found to be take placed at this value. Fig. S5 compares the final solution $\mathrm{pH}$ values in the SOP and COP experiments. As shown in Fig. S5, the $\mathrm{pH}$ of the solution at the end of the experiments considerably dropped in the SOP experiments, indicating that some acidic intermediates may be formed through the degradation of ACT. On the contrast, by adding $\mathrm{SnNaC}-550$ catalyst to the ozonation process, the solution $\mathrm{pH}$ was remained constant at neutral value during the experiments. It can be explained by the presence of an alkaline agent $(\mathrm{NaOH})$ in the $\mathrm{SnNaC}-550$ structure. The pHzpc of SnNaC550 was measured 7.8 (Fig. S6).

Fig. 5 shows that by the addition of tert-butanol, as a most common -OH scavenger, the ACT degradation did not change considerably (Moussavi et al., 2018), while the addition of salicylic acid reduced the ACT degradation efficiency to $41.6 \%$. This can be explained by the reaction rate constant which has been reported $1.7 \times 10^{9} \mathrm{M}^{-1} \mathrm{~s}^{-1}$ for ACT reaction with ${ }^{\bullet} \mathrm{OH}$ (Yang et al., 2009), while the reaction rate constants for the reaction of ${ }^{\bullet} \mathrm{OH}$ with the tert-butanol, and salicylic acid have been reported $6 \times 10^{8}$ and $2.2 \times 10^{10} \mathrm{M}^{-1} \mathrm{~s}^{-1}$, respectively (Crittenden et al., 2012). Collectively, the remarkable reduction observed in ACT removal efficiency by salicylic acid, as a super ${ }^{\bullet} \mathrm{OH}$ scavenger, highlights that ${ }^{\circ} \mathrm{OH}$ species generated in the $\mathrm{COP}$ using $\mathrm{SnNaC}-550$ as catalyst are responsible for the main part of ACT degradation.

The generation of ${ }^{\bullet} \mathrm{OH}$ species in the heterogeneous COP could be explained by the interaction between basic functional groups on the surface of SnNaC-550 and ozone molecules (Mashayekh-Salehi et al., 2017). As dissolved ozone has electrophilic characteristics, the basic functional groups of the catalyst surface such as $\mathrm{OH}^{-}$play major roles in transforming $\mathrm{O}_{3}$ molecules into the ${ }^{\bullet} \mathrm{OH}$ radicals (Sánchez-Polo et al., 2005). This explanation is in line with our results presented in Fig. 3, where a broad band density of - $\mathrm{OH}$ groups (strong broad band at $3433 \mathrm{~cm}^{-1}$ ) was detected on the surface of SnNaC-550 nanoparticles. Since ozone molecules have both nucleophilic and electrophilic sites, it could be expected that the dissolved ozone molecules interact with the both $\mathrm{H}$ (as electrophilic) and $\mathrm{O}$ (as nucleophilic) atoms of -OH groups exist on the surface of SnNaC-550 nanoparticles. Thus, it can be assumed that the - $\mathrm{OH}$ groups may initiate the ozone decomposition and thereby accelerate the production of ${ }^{\bullet} \mathrm{OH}$ (Zhang et al., 2008), and subsequently increase ACT degradation. In order to confirm the hypothesis that ozone is decomposed in the presence of $\mathrm{SnO}_{2}$, we performed mass balance analysis with measuring the concentration of ozone in the feed gas and off-gas streams in the SOP and COP (under the conditions of $1.3 \mathrm{~g} / \mathrm{L}$ of

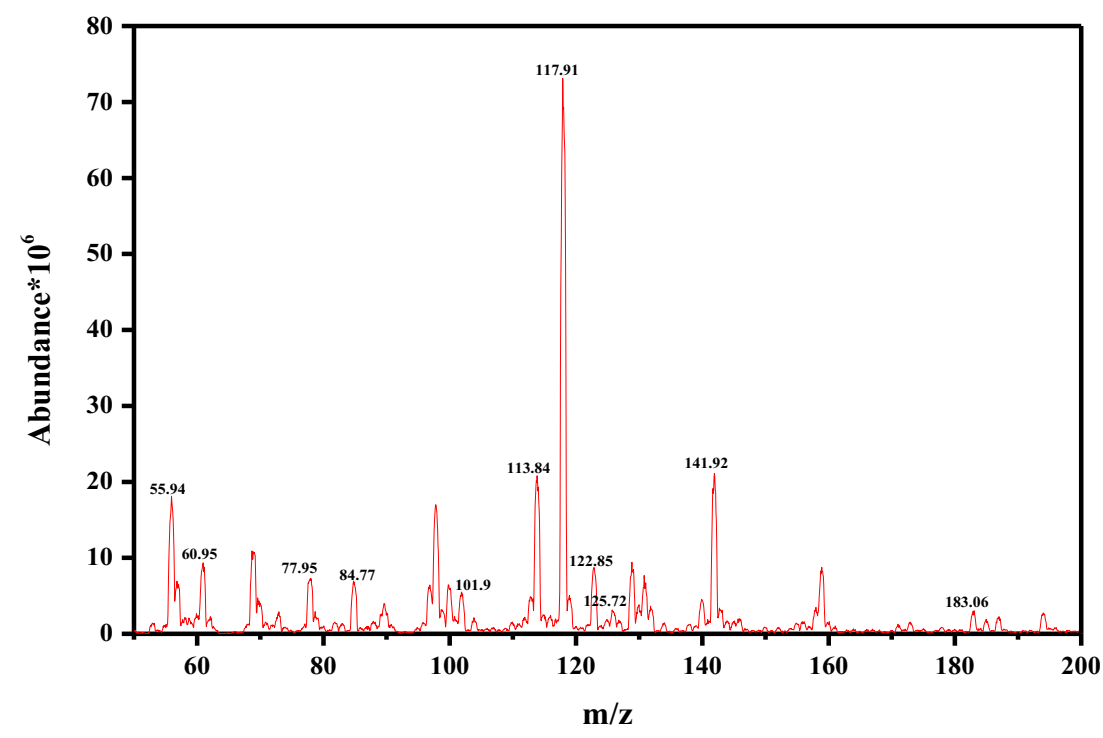

Fig. 6. LC/MS spectra of ACT degradation by-products in the positive ESI mode $\left[\mathrm{M}+\mathrm{H}^{+}\right]$of ACT and its $m / z$ signals. 
(1)

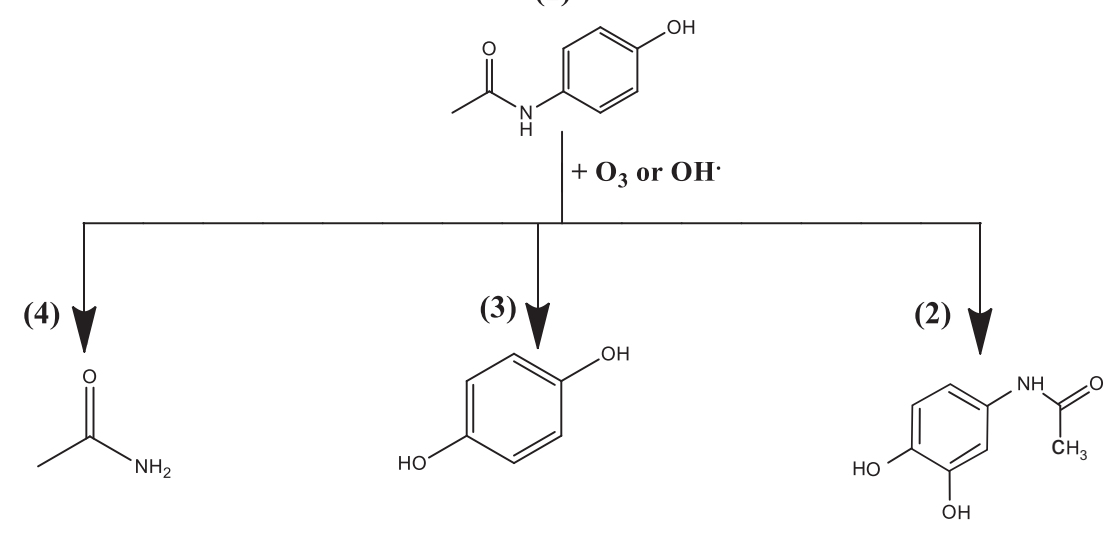<smiles>CCCCCCCC(C)=O</smiles><smiles>CCCC</smiles><smiles>CC(=O)O</smiles>

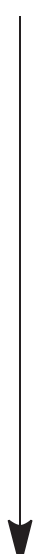<smiles>CCCCCC(C)=O</smiles><smiles>CCC(CC)[N+](=O)[O-]</smiles>
$\mathrm{CO}_{2}, \mathrm{H}_{2} \mathrm{O}, \mathrm{NH}_{4}{ }^{+}, \mathrm{NO}_{3}{ }^{-}$

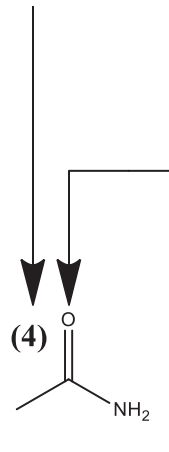

(7)<smiles>O=C(O)CO</smiles>

(8)<smiles>O=C(O)C(O)C(=O)O</smiles><smiles>O=C(O)CC(O)C(=O)O</smiles>

(12)

(11)<smiles>CC(=O)OC(C)=O</smiles><smiles>CCCCC</smiles><smiles>O=CC(C(=O)O)C(=O)O</smiles>

(13)<smiles>CCC</smiles><smiles>O=C(O)C(=O)O</smiles>

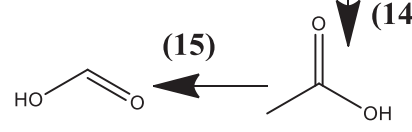

Fig. 7. The proposed pathway of ACT degradation in the COP experiment using SnNaC-550 as catalyst (1-acetaminophen, 2-2-hydroxy-4-(Nacetyl) aminophenol 3-hydroquinone, 4-acetamide, 5-hydroxy-acetic acid, 6-oxamic acid, 7-glycolic acid, 8-tartronic acid, 9-malic acid, 10-nitrate, 11-glyoxylic acid, 12 ketomalonic acid, 13-oxalic acid, 14-acetic acid, 15-formic acid).

$\mathrm{SnO}_{2}$ was used at $\mathrm{pH} 7$, an ACT concentration of $50 \mathrm{mg} / \mathrm{L}$, an $\mathrm{O}_{3}$ dosage of $1.6 \mathrm{mg} \mathrm{O} 3 / \mathrm{min}$ and a reaction time of $10 \mathrm{~min}$ ), and compared the results. The ozone concentration in the inlet gas and outlet gas streams was measured by an ozone analyzer (BMT 964 C, RMT MESSTECHIK, WEDECO company, BERLIN, Germany). The percentage of ozone decomposition was calculated from the ratio of the concentration of outlet ozone to the inlet one. Based on the results, the ozone decomposition of $18.75 \%$ and $77.5 \%$ was observed for the SOP and COP, respectively operated under similar $\mathrm{O}_{3}$ dosage. These findings approve the above mentioned hypothesis and indicate considerable ozone decomposition in the integrated $\mathrm{SnO}_{2}$-ozonation process. Moreover, - $\mathrm{OH}$ species produced in the $\mathrm{COP}$ are also responsible for the $\mathrm{O}_{3}$ decomposition as well as the improved ACT degradation efficiency. Previous studies has shown that hard-base anions such as carbonate/ bicarbonate, sulfate and phosphate are dependent to the Lewis acids and thus can capture the active sites of the catalysts surface, causing a reduction in decomposition of ozone and in turn a decrease in catalytic activity (Joseph et al., 2000; Ma and Graham, 1999; Schmitt and Pietrzyk, 1985). In contrast, as shown in Fig. 5, the degradation of ACT was not considerably affected in the presence of tested inorganic radical inhibitors in the COP. It is possible that the generated ${ }^{\circ} \mathrm{OH}$ was transferred into the bulk solution and then reacted with ACT molecules mostly in the bulk solution rather than on the catalyst surface. Accordingly, the four following mechanisms may be hypothesized for ACT 

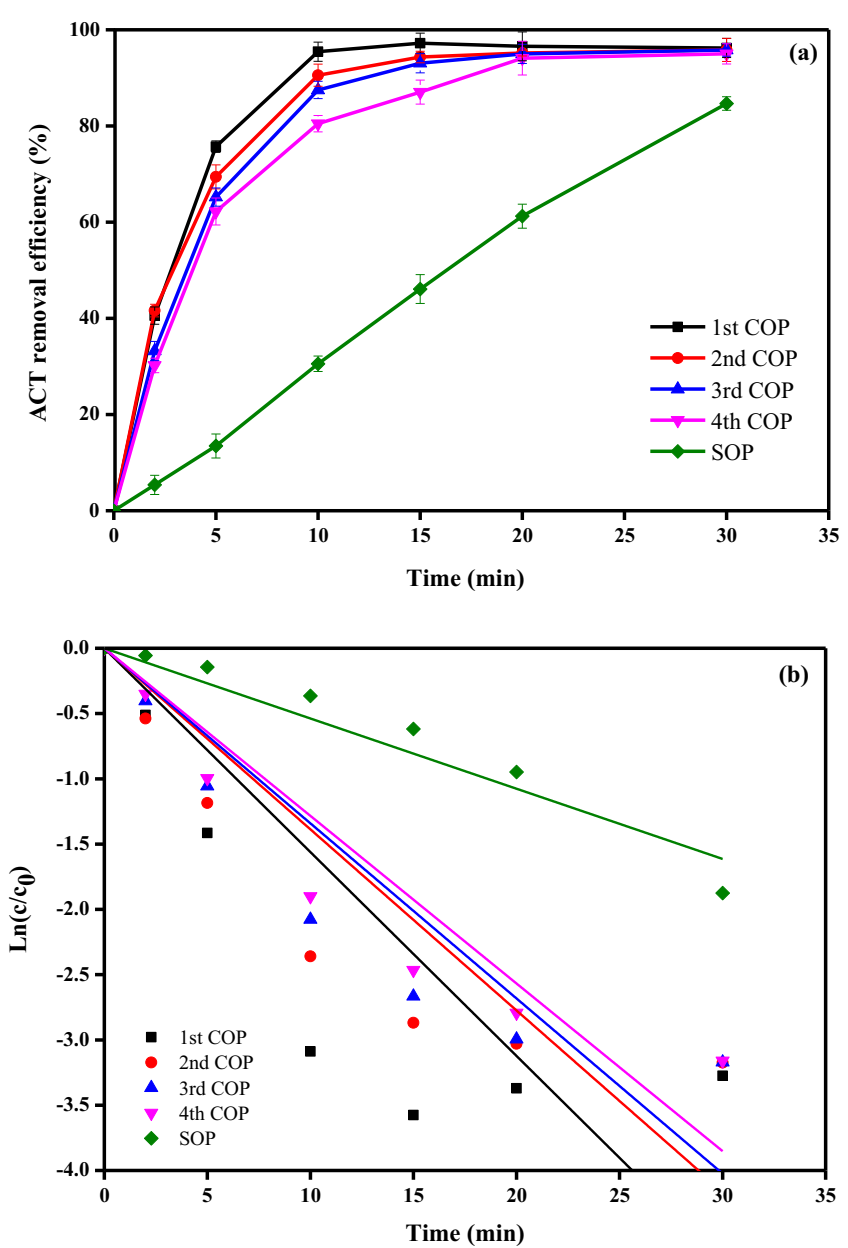

Fig. 8. The reusability of SnNaC-550 during oxidation of ACT as a function of reaction time in the COP (a) with the with the adjusted line equation (b) (conditions: pH: 7; ACT concentration: $50 \mathrm{mg} / \mathrm{L} ; \mathrm{SnO}_{2}$ dosage: $1.3 \mathrm{~g} / \mathrm{L}$ and $\mathrm{O}_{3}$ dosage: $\left.1.6 \mathrm{mg} \mathrm{O}_{3} / \mathrm{min}\right)$. .

degradation in the COP:

- Oxidation via direct reaction of ACT molecules with ozone on the catalyst surface:

$$
\begin{aligned}
& \mathrm{SnO}_{2}^{-\mathrm{O}_{3}}+\mathrm{ACT} \rightarrow \text { intermediates }+\mathrm{H}_{2} \mathrm{O}+\mathrm{CO}_{2} \\
& \mathrm{SnO}_{2}{ }^{-\mathrm{ACT}}+\mathrm{O}_{3} \rightarrow \text { intermediates }+\mathrm{H}_{2} \mathrm{O}+\mathrm{CO}_{2}
\end{aligned}
$$

- ACT oxidation with generated radicals on the catalyst surface:

$$
\begin{aligned}
& \mathrm{SnO}_{2}-\mathrm{s}+\mathrm{O}_{3} \rightarrow \mathrm{SnO}_{2}-\mathrm{s}^{\mathrm{O}=\mathrm{O}-\mathrm{O}} \rightarrow \mathrm{SnO}_{2}{ }^{-\mathrm{s}^{\mathrm{0}}}+\mathrm{O}_{2} \\
& \mathrm{SnO}_{2}{ }^{-\mathrm{s}^{\mathrm{0}}}+2 \mathrm{H}_{2} \mathrm{O}+\mathrm{O}_{3} \rightarrow \mathrm{SnO}_{2}-\mathrm{S}^{\left(\mathrm{OH}^{\bullet}\right)_{2}}+3 \quad \mathrm{OH}+2 \mathrm{O}_{2} \\
& \mathrm{SnO}_{2}-\mathrm{S} \quad(\dot{\mathrm{O}} \mathrm{H})_{2}+\mathrm{ACT} \rightarrow \text { intermediates }+\mathrm{H}_{2} \mathrm{O}+\mathrm{CO}_{2} \\
& \mathrm{SnO}_{2}{ }^{-\mathrm{ACT}}+\dot{\mathrm{OH}} \rightarrow \text { intermediates }+\mathrm{H}_{2} \mathrm{O}+\mathrm{CO}_{2}
\end{aligned}
$$

- Direct oxidation of ACT molecules with ozone in the bulk solution:

$$
\mathrm{O}_{3}+\mathrm{ACT} \rightarrow \text { intermediates }+\mathrm{H}_{2} \mathrm{O}+\mathrm{CO}_{2}
$$

- ACT oxidation with generated radical in the bulk solution:
$\dot{\mathrm{OH}}+\mathrm{ACT} \rightarrow$ intermediates $+\mathrm{H}_{2} \mathrm{O}+\mathrm{CO}_{2}$

The sites of Lewis acid on the surface of $\mathrm{SnO}_{2}$ nanoparticles are illustrated with the suffix $S$ and are accessible to react with ozone. According to the above hypothesis mechanisms and the results obtained by testing the radical scavengers, the ACT most probably is degraded through the reaction proposed in Eq. (12). However other mentioned mechanisms might be also involved partially.

\subsection{Identification of intermediates and proposed pathways of ACT degradation in $\mathrm{COP}$}

Fig. 6 illustrates the LC/MS spectra of ACT degradation by-products and related signals and abundance at $m / z$ of $50-200$ in $\left[\mathrm{M}+\mathrm{H}^{+}\right]$. Moreover, the molecular weight and molecular structure of each identified intermediate is summarized in Table S3. According to Fig. 5, no ACT signal $(m / z=152)$ was detected and the spectrum mainly contains short signals (except $m / z=117.9$ ) indicating effective ACT degradation in the COP under the operating conditions (Fig. 1) (Skoumal et al., 2006). As shown in Fig. 6 , the $m / z=117.9$ was the most abundant identified signal was related to the fragmentation of ACT into tartronic acid and ketomalonic acid. Abundance of these linear structures identified in the treated ACT solution demonstrates the breakage of the benzene ring by the ${ }^{\circ} \mathrm{OH}$ radicals. Other $\mathrm{m} / \mathrm{z}$ signals of $55.94,60.95$, $77.95,84.77,113.84,125.72,141.92$ and 183.06 , corresponding to acetamide, tartronic acid, glycolic acid, oxamic acid, oxalic acid, hydroxy-acetic acid, formic acid and malic acid, respectively, reconfirm the high degree of aromatic ring decomposition (Skoumal et al., 2006; Andreozzi et al., 2003) Presence of moderate $m / z=101.9$ in the LC/MS chromatogram corresponds to the reaction of ${ }^{\circ} \mathrm{OH}$ with linear intermediates which result in the generation of simple and final products such as nitrate (Mashayekh-Salehi et al., 2017). The stoichiometric level of $\mathrm{N}$ in the $50 \mathrm{mg} / \mathrm{L}$ ACT solution was calculated to be $20 \mathrm{mg} / \mathrm{L}$. The concentration of nitrate in the COP treated solution was measured around $17.6 \mathrm{mg} \mathrm{N} / \mathrm{L}$, implying that $\mathrm{N}$ in the ACT is well mineralized to nitrate. With the presence of a benzene ring structure, the presence of hydroquinone (at $m / z=122.85$ ) may be due to single attack of ozone molecules to ACT and insufficient energy to cleave the aromatic ring at initial stages of ACT degradation (Skoumal et al., 2006).

Based on identified intermediates derived from LC/MS analysis (Table S3) and related studies (Skoumal et al., 2006; Andreozzi et al., 2003; Neamţu et al., 2013), a proposed pathway for degradation of ACT in the SnNaC-550-based COP is shown in Fig. 7. Accordingly, two main routes can be considered for ACT degradation: (1) $\mathrm{O}_{3}$ molecules that directly attack the benzene ring of ACT leading to hydroquinone generation and (2) ${ }^{\circ} \mathrm{OH}$ attack in parallel to the $\mathrm{C}(2)$ and $\mathrm{C}(4)$ position causing generation of saturated and mineral compounds. The second route is most dominant.

\subsection{Catalyst reusability}

Stability and reusability of catalysts throughout their successive usage is one of the most important properties from a practical point of view. The reusability of SnNaC-500 (optimized catalyst) was evaluated for four repetitive COP experiments under optimum experimental conditions. Although the optimum catalytic activity of ACT degradation in the present study was attained at a reaction time of $10 \mathrm{~min}$, to confirm the reusability and stability of the catalyst, it was extended to $30 \mathrm{~min}$. The ACT degradation efficiency after each cycle was measured according to the reaction time and results are shown in Fig. 8. The percentage of ACT degradation was not significantly influenced after four repetitive times of reusing SnNaC-500 and remained higher than 95\%, while ACT degradation percentage was about $97 \%$ for the fresh SnNaC-500. Moreover, at the end of COP tests, the concentration of dissolved Sn was measured $50 \mu \mathrm{g} / \mathrm{L}$ (ICP-MS, Alanlytik Jena model PlasmaQuant 
MS), which did not exceed the standard limits (World Health Organization, 2004). Accordingly, it can be concluded that optimized $\mathrm{SnO}_{2}$ preparation produced in this study maintains its catalytic potential even after four successive usages and could be considered as a stable and reusable nanocatalyst for the degradation of ACT. Moreover, the reusability of this catalyst confirms again that the principal mechanism underlying the ACT degradation in this study was catalytic reaction rather than other mechanisms including adsorption.

\section{Conclusions}

In the present study, a novel sol-gel method was employed to produce several nano- $\mathrm{SnO}_{2}$ preparations and combined with the ozonation process (COP) to remove ACT from aqueous solution, as a model of refractory water pollutants. The maximum catalytic activity of ACT degradation was obtained by $\mathrm{SnO}_{2}$ prepared with $\mathrm{SnCl}_{4}$ as $\mathrm{Sn}$ source, $\mathrm{NaOH}$ as alkaline agent, CTAB as capping agent and at calcination temperature of $550{ }^{\circ} \mathrm{C}(\mathrm{SnNaC}-550)$. In contrast, the minimum catalytic activity was for the catalyst synthesized with $\mathrm{SnSO}_{4}$ as $\mathrm{Sn}$ source, $\mathrm{NH}_{4} \mathrm{OH}$ as alkaline agent and without capping agent (SONH-550). The optimized catalyst had a nanocrystalline structure with a specific surface area of $81 \mathrm{~m}^{2} / \mathrm{g}$, and was cubic in shape and had an average particle size of $5.5 \mathrm{~nm}$. The degradation and mineralization rates of ACT in the COP (when SnNaC-550 was used as catalyst) were 7.805 and 4.7 times greater than those values obtained in the SOP, respectively. Mechanistically, we showed that $\mathrm{SnNaC}-550$ could decompose $\mathrm{O}_{3}$ which in turn increases ${ }^{\circ} \mathrm{OH}$ generation and is responsible for the ACT degradation in the COP. Based on the TOC reduction results, SnNaC-550-based ozonation was able to mineralize ACT for $84 \%$ at a reaction time of $30 \mathrm{~min}$. Our findings show that short-chain carboxylic acids were the major oxidation by-products of ACT degradation by SnNaC-550-based COP. Collectively, according to the findings of present study; the sol-gel method has the potential to be considered as a practical technique to synthesize stable and reusable $\mathrm{SnO}_{2}$ nanoparticles to catalyse the removal of ACT from water environments.

\section{CRediT authorship contribution statement}

Fatemeh Rashidashmagh: Investigation, Preparation catalyst, Experiment runs, Draw diagrams. Yasmina Doekhi-Bennani: Investigation, Preparation catalyst, Experiment runs, Draw diagrams. Mostafa Tizghadam-Ghazani: Supervision, Guidance in project steps. Jan Peter van der Hoek: Interpretation of the reported study, Visualization, Guidance in project steps. Ali Mashayekh-Salehi: Conceptualization, Methodology, Software, Formal analysis, Resources, Writing - original draft, Supervision. Bas S.G.J. Heijman: Conceptualization, Methodology. Kamyar yaghmaeian: Funding acquisition, Project administration.

\section{Declaration of Competing Interest}

The authors declare that they have no known competing financial interests or personal relationships that could have appeared to influence the work reported in this paper.

\section{Acknowledgements}

This research was financially supported by the Department of Water Management, Delft University of Technology, Delft, Netherlands, which was highly appreciated. The authors would like to thank the Department of Quantum Nanoscience, part of the Kavli Institute of Nanoscience at the Delft University of Technology, for the use of the TEM and HRTEM facilities. The authors also would like to give their special thanks to technical support provided by the Water and Environmental Engineering Faculty, Shahid Beheshti University, the Department of Environmental Health Engineering, School of Health, Shahroud University of
Medical Sciences and the Department of Environmental Health Engineering, Tehran University of Medical Sciences (TUMH) Iran.

\section{Appendix A. Supporting information}

Supplementary data associated with this article can be found in the online version at doi:10.1016/j.jhazmat.2020.124154.

\section{References}

Andreozzi, R., Caprio, V., Marotta, R., Radovnikovic, A., 2003. Ozonation and H2O2/UV treatment of clofibric acid in water: a kinetic investigation. J. Hazard. Mater. 103, 233-246. https://doi.org/10.1016/j.jhazmat.2003.07.001.

Esplugas, S., Bila, D.M., Krause, L.G.T., Dezotti, M., 2007. Ozonation and advanced oxidation technologies to remove endocrine disrupting chemicals (EDCs) and pharmaceuticals and personal care products (PPCPs) in water effluents. J. Hazard. Mater. 149, 631-642. https://doi.org/10.1016/j.jhazmat.2007.07.073.

Feng L., Non-steroidal anti-inflammatory pharmaceuticals from To cite this version: HAL Id : tel-00952080 Processes for the Removal of Residual Non-steroidal AntiInflammatory Pharmaceuticals From, 2014.

Fu, C., Wang, J., Yang, M., Su, X., Xu, J., Jiang, B., 2011. Effect of la doping on microstructure of $\mathrm{SnO} 2$ nanopowders prepared by co-precipitation method. J. Non Cryst. Solids 357, 1172-1176. https://doi.org/10.1016/j.jnoncrysol.2010.10.019.

Gogoi, A., Mazumder, P., Tyagi, V.K., Tushara Chaminda, G.G., An, A.K., Kumar, M., 2018. Occurrence and fate of emerging contaminants in water environment: a review. Groundw. Sustain. Dev. 6, 169-180. https://doi.org/10.1016/j. gsd.2017.12.009.

Gonçalves, A.G., órfão, J.J.M., Pereira, M.F.R., 2012. Catalytic ozonation of sulphamethoxazole in the presence of carbon materials: catalytic performance and reaction pathways. J. Hazard. Mater. 239-240, 167-174. https://doi.org/10.1016/j. jhazmat.2012.08.057.

Gondal, M.A., Drmosh, Q.A., Saleh, T.A., 2010. Preparation and characterization of SnO 2 nanoparticles using high power pulsed laser. Appl. Surf. Sci. 256, 7067-7070. https://doi.org/10.1016/j.apsusc.2010.05.027.

Gupta, V.K., Fakhri, A., Agarwal, S., Bharti, A.K., Naji, M., Tkachev, A.G., 2018. Preparation and characterization of TiO2 nanofibers by hydrothermal method for removal of Benzodiazepines (Diazepam) from liquids as catalytic ozonation and adsorption processes. J. Mol. Liq. 249, 1033-1038. https://doi.org/10.1016/j. molliq.2017.11.144.

Hartmann, J., Wuijts, S., Van Der Hoek, J.P., De Roda Husman, A.M., 2019. Use of literature mining for early identification of emerging contaminants in freshwater resources. Environ. Evid. 8, 1-15. https://doi.org/10.1186/s13750-019-0177-z.

Saeid, S., Tolvanen, P., Kumar, N., Eränen, K., Peltonen, J., Peurla, M., Mikkola, J.P., Franz, A., Salmi, T., 2018. Advanced oxidation process for the removal of ibuprofen from aqueous solution: a non-catalytic and catalytic ozonation study in a semi-batch reactor. Appl. Catal. B Environ. 230, 77-90. https://doi.org/10.1016/j. apcatb.2018.02.021.

Sui, M., Xing, S., Sheng, L., Huang, S., Guo, H., 2012. Heterogeneous catalytic ozonation of ciprofloxacin in water with carbon nanotube supported manganese oxides as catalyst. J. Hazard. Mater. 227-228, 227-236. https://doi.org/10.1016/j. jhazmat.2012.05.039.

Taghvaei, V., Habibi-Yangjeh, A., Behboudnia, M., 2009. Preparation and characterization of $\mathrm{SnO} 2$ nanoparticles in aqueous solution of [EMIM] [EtSO4] as a low cost ionic liquid using ultrasonic irradiation. Powder Technol. 195, 63-67. https://doi.org/10.1016/j.powtec.2009.05.023.

Taheran, M., Naghdi, M., Brar, S.K., Verma, M., Surampalli, R.Y., 2018. Emerging contaminants: here today, there tomorrow!, Environ. Nanotechnol., Monit. Manag 10, 122-126. https://doi.org/10.1016/j.enmm.2018.05.010.

Tambosi, J.L., de Sena, R.F., Favier, M., Gebhardt, W., José, H.J., Schröder, H.F., R., de Fatima Peralta Muniz Moreira, 2010. Removal of pharmaceutical compounds in membrane bioreactors (MBR) applying submerged membranes. Desalination 261, 148-156. https://doi.org/10.1016/j.desal.2010.05.014.

Thommes, M., 2010. Physical adsorption characterization of nanoporous materials. Chem. -Ing. -Tech. 82, 1059-1073. https://doi.org/10.1002/cite.201000064.

Turgut, G., Sönmez, E., 2014. Synthesis and characterization of Mo doped SnO2 thin films with spray pyrolysis. Superlattices Micro 69, 175-186. https://doi.org/ 10.1016/j.spmi.2014.02.009.

Wang, J., Bai, Z., 2017. Fe-based catalysts for heterogeneous catalytic ozonation of emerging contaminants in water and wastewater. Chem. Eng. J. 312, 79-98. https:// doi.org/10.1016/j.cej.2016.11.118.

World Health Organization, 2004. Guidelines for drinking-water quality. Inorganic Tin in Drinking-Water.

American Public Health Association, American Water Works Association, Water Environment Federation, 1998. Standard Methods for the Examination of Water and Wastewater, twentieth edition. APHA-AWWA-WEF.

Aramendía, M.A., Borau, V., Jiménez, C., Marinas, J.M., Ruiz, J.R., Urbano, F.J., 2003. Influence of the preparation method on the structural and surface properties of various magnesium oxides and their catalytic activity in the Meerwein-PonndorfVerley reaction. Appl. Catal. A Gen. 244, 207-215. https://doi.org/10.1016/S0926860X(02)00213-2.

Aziz, M., Saber Abbas, S., Wan Baharom, W.R., 2013. Size-controlled synthesis of SnO2 nanoparticles by sol-gel method. Mater. Lett. 91, 31-34. https://doi.org/10.1016/j. matlet.2012.09.079. 
Barnes, K.K., Kolpin, D.W., Furlong, E.T., Zaugg, S.D., Meyer, M.T., Barber, L.B., 2008. A national reconnaissance of pharmaceuticals and other organic wastewater contaminants in the United States - I) groundwater. Sci. Total Environ. 402, 192-200. https://doi.org/10.1016/j.scitotenv.2008.04.028.

Begum, S., Ahmaruzzaman, M., 2018. CTAB and SDS assisted facile fabrication of $\mathrm{SnO} 2$ nanoparticles for effective degradation of carbamazepine from aqueous phase: a systematic and comparative study of their degradation performance. Water Res 129, 470-485. https://doi.org/10.1016/j.watres.2017.11.031.

Begum, S., Devi, T.B., Ahmaruzzaman, M., 2016. Surfactant mediated facile fabrication of $\mathrm{SnO} 2$ quantum dots and their degradation behavior of humic acid. Mater. Lett. 185, 123-126. https://doi.org/10.1016/j.matlet.2016.07.028.

Cao, X., Shu, Y.C., Hu, Y.N., Li, G.P., Liu, C., 2013. Integrated process of large-scale and size-controlled $\mathrm{SnO} 2$ nanoparticles by hydrothermal method. Trans. Nonferrous Met. Soc. China 23, 725-730. https://doi.org/10.1016/S1003-6326(13)62521-2.

Chang, P.Y., Doong, R. an, 2019. Microwave-assisted synthesis of $\mathrm{SnO} 2 /$ mesoporous carbon core-satellite microspheres as anode material for high-rate lithium ion batteries. J. Alloy. Compd. 775, 214-224. https://doi.org/10.1016/j. jallcom.2018.10.038.

Crittenden J.C., Rhodes Trussell R., Hand D.W., Howe K.J, Tchobanoglous G., Introduction 1-1 History of the Development of Water Treatment 1-2 Health and Environmental Concerns 1-3 Constituents of Emerging Concern Number of Possible Contaminants Pharmaceuticals and Personal Care Products Nanoparticles Other Constituents of Emerg, 2012 1-16.

Das, M., Roy, S., 2019. Preparation, characterization and properties of newly synthesized SnO2-polycarbazole nanocomposite via room temperature solution phase synthesis process. Mater. Today Proc. 18, 5438-5446. https://doi.org/10.1016/j. matpr.2019.07.573.

Deng, H., Lamelas, F.J., Hossenlopp, J.M., 2003. Synthesis of tin oxide nanocrystalline phases via use of tin(II) halide precursors. Chem. Mater. 15, 2429-2436. https://doi. org $/ 10.1021 / \mathrm{cm} 020973 \mathrm{t}$.

Dimitrov, M., Tsoncheva, T., Shao, S., Köhn, M., 2010. Novel preparation of nanosized mesoporous SnO2 powders: physicochemical and catalytic properties. Appl. Catal. B Environ. 94, 158-165. https://doi.org/10.1016/j.apcatb.2009.11.004.

Ebele, A.J., Abou-Elwafa Abdallah, M., Harrad, S., 2017. Pharmaceuticals and personal care products (PPCPs) in the freshwater aquatic environment. Emerg. Contam. 3, 1-16. https://doi.org/10.1016/j.emcon.2016.12.004.

Ensano, B.M.B., Borea, L., Naddeo, V., Belgiorno, V., de Luna, M.D.G., Ballesteros, F.C., 2017. Removal of pharmaceuticals from wastewater by intermittent electrocoagulation. Water 9, 1-15. https://doi.org/10.3390/w9020085.

Escolà Casas, M., Chhetri, R.K., Ooi, G., Hansen, K.M.S., Litty, K., Christensson, M., Kragelund, C., Andersen, H.R., Bester, K., 2015. Biodegradation of pharmaceuticals in hospital wastewater by a hybrid biofilm and activated sludge system (Hybas). Sci. Total Environ. 530-531, 383-392. https://doi.org/10.1016/j scitotenv.2015.05.099.

Gharibi, H., Sadeghi, S., Golmohammadi, F., 2016. Electrooxidation of ethanol on highly active and stable carbon supported PtSnO2 and its application in passive direct ethanol fuel cell: effect of tin oxide synthesis method. Electrochim. Acta 190, 1100-1112. https://doi.org/10.1016/j.electacta.2015.12.208.

Hartmann, J., van Driezum, I., Ohana, D., Lynch, G., Berendsen, B., Wuijts, S., van der Hoek, J.P., de roda Husman, A.M., 2020. The effective design of sampling campaigns for emerging chemical and microbial contaminants in drinking water and its resources based on literature mining. Sci. Total Environ. 742, 140546 https://doi. org/10.1016/j.scitotenv.2020.140546.

Houtman, C.J., Kroesbergen, J., Lekkerkerker-Teunissen, K., van der Hoek, J.P., 2014. Human health risk assessment of the mixture of pharmaceuticals in Dutch drinking water and its sources based on frequent monitoring data. Sci. Total Environ. 496, 54-62. https://doi.org/10.1016/j.scitotenv.2014.07.022.

Huang, Y., Luo, M., Xu, Z., Zhang, D., Li, L., 2019. Catalytic ozonation of organic contaminants in petrochemical wastewater with iron-nickel foam as catalyst. Sep. Purif. Technol. 211, 269-278. https://doi.org/10.1016/j.seppur.2018.09.080.

Jahnavi, V.S., Tripathy, S.K., Ramalingeswara Rao, A.V.N., 2019. Structural, optical, magnetic and dielectric studies of $\mathrm{SnO} 2$ nano particles in real time applications. Phys. B Condens. Matter 565, 61-72. https://doi.org/10.1016/j.physb.2019.04.020.

Joseph, Y., Ranke, W., Weiss, W., 2000. Water on FeO(111) and Fe3O4(111): adsorption behavior on different surface terminations. J. Phys. Chem. B. 104, 3224-3236. https://doi.org/10.1021/jp9932012.

Journal C., N o 2 -o 2, 47 (2003) 2-4. https://doi.org/10.16647/j.cnki.cn15-1369/ X.2018.01.066

Kanakaraju, D., Glass, B.D., Oelgemöller, M., 2018. Advanced oxidation processmediated removal of pharmaceuticals from water: a review. J. Environ. Manag. 219, 189-207. https://doi.org/10.1016/j.jenvman.2018.04.103.

Khataee, A., Rad, T.S., Fathinia, M., 2017. The role of clinoptilolite nanosheets in catalytic ozonation process: insights into the degradation mechanism, kinetics and the toxicity. J. Taiwan Inst. Chem. Eng. 77, 205-215. https://doi.org/10.1016/j. jtice.2017.05.004.

Klavarioti, M., Mantzavinos, D., Kassinos, D., 2009. Removal of residual pharmaceuticals from aqueous systems by advanced oxidation processes. Environ. Int. 35, 402-417. https://doi.org/10.1016/j.envint.2008.07.009.

Kolpin D. , Furlong E. , Meyer M , Barber L. , Zaugg S. , Buxton H. , Meyer M.T. , Pharmaceuticals, Hormones, and Other Organic Wastewater Contaminants in U.S . Streams , 1999-2000: A National Reconnaissance Other Organic Wastewater Contaminants in U . S . Streams, 1999-2000 : A National Reconnaissance, US Geol. Surv. (2000) 1999-2000. 〈https://digitalcommons.unl.edu/cgi/viewcontent.cgi? referer=https://www.google.com/ \&httpsredir $=1 \&$ article $=1064 \&$ context $=$ usgsstaffpub $\rangle$.
Kumar, A., Yadav, N., Bhatt, M., Mishra, N.K., Chaudhary, P., Singh, R., 2015. Sol-Gel derived nanomaterials and it's applications: a review. Res. J. Chem. Sci. 5, 98-105 (www.isca.me).

Lin, C.J., Yang, W.T., Chou, C.Y., Liou, S.Y.H., 2016. Hollow mesoporous TiO2 microspheres for enhanced photocatalytic degradation of acetaminophen in water. Chemosphere 152, 490-495. https://doi.org/10.1016/j.chemosphere.2016.03.017.

Luján-Facundo, M.J., Iborra-Clar, M.I., Mendoza-Roca, J.A., Alcaina-Miranda, M.I., 2019. Pharmaceutical compounds removal by adsorption with commercial and reused carbon coming from a drinking water treatment plant. J. Clean. Prod. 238 https://doi.org/10.1016/j.jclepro.2019.117866.

de Luna, M.D.G., Briones, R.M., Su, C.C., Lu, M.C., 2013. Kinetics of acetaminophen degradation by Fenton oxidation in a fluidized-bed reactor. Chemosphere 90 , 1444-1448. https://doi.org/10.1016/j.chemosphere.2012.09.003.

Luo, Y., Guo, W., Ngo, H.H., Nghiem, L.D., Hai, F.I., Zhang, J., Liang, S., Wang, X.C., 2014. A review on the occurrence of micropollutants in the aquatic environment and their fate and removal during wastewater treatment. Sci. Total Environ. 473-474, 619-641. https://doi.org/10.1016/j.scitotenv.2013.12.065.

Luque, P.A., Nava, O., Soto-Robles, C.A., Chinchillas-Chinchillas, M.J., GarrafaGalvez, H.E., Baez-Lopez, Y.A., Valdez-Núñez, K.P., Vilchis-Nestor, A.R., CastroBeltrán, A., 2020. Improved photocatalytic efficiency of SnO2 nanoparticles through green synthesis. Opt. (Stuttg. ) 206. https://doi.org/10.1016/j.ijleo.2020.164299.

Ma, J., Graham, N.J.D., 1999. Degradation of atrazine by manganese-catalysed ozonation: influence of humic substances. Water Res. 33, 785-793. https://doi.org/ 10.1016/S0043-1354(98)00266-8.

Mashayekh-Salehi, A., Moussavi, G., 2016. Removal of acetaminophen from the contaminated water using adsorption onto carbon activated with $\mathrm{NH} 4 \mathrm{Cl}$. Desalin. Water Treat. 57, 12861-12873. https://doi.org/10.1080/19443994.2015.1051588.

Mashayekh-Salehi, A., Moussavi, G., Yaghmaeian, K., 2017. Preparation, characterization and catalytic activity of a novel mesoporous nanocrystalline $\mathrm{MgO}$ nanoparticle for ozonation of acetaminophen as an emerging water contaminant. Chem. Eng. J. 310, 157-169. https://doi.org/10.1016/j.cej.2016.10.096.

Meffe, R., de Bustamante, I., 2014. Emerging organic contaminants in surface water and groundwater: a first overview of the situation in Italy. Sci. Total Environ. 481, 280-295. https://doi.org/10.1016/j.scitotenv.2014.02.053.

Moussavi, G., Mahmoudi, M., 2009. Degradation and biodegradability improvement of the reactive red 198 azo dye using catalytic ozonation with $\mathrm{MgO}$ nanocrystals. Chem. Eng. J. 152, 1-7. https://doi.org/10.1016/j.cej.2009.03.014.

Moussavi, G., Khosravi, R., Omran, N.R., 2012. Development of an efficient catalyst from magnetite ore: Characterization and catalytic potential in the ozonation of water toxic contaminants. Appl. Catal. A Gen. 445-446, 42-49. https://doi.org/10.1016/j. apcata.2012.08.002.

Moussavi, G., Pourakbar, M., Aghayani, E., Mahdavianpour, M., 2018. Investigating the aerated VUV/PS process simultaneously generating hydroxyl and sulfate radicals for the oxidation of cyanide in aqueous solution and industrial wastewater. Chem. Eng. J. 350, 673-680. https://doi.org/10.1016/j.cej.2018.05.178.

Nawaz, F., Cao, H., Xie, Y., Xiao, J., Chen, Y., Ghazi, Z.A., 2017. Selection of active phase of MnO2for catalytic ozonation of 4-nitrophenol. Chemosphere 168, 1457-1466. https://doi.org/10.1016/j.chemosphere.2016.11.138.

Neamţu, M., Bobu, M., Kettrup, A., Siminiceanu, I., 2013. Ozone photolysis of paracetamol in aqueous solution. J. Environ. Sci. Heal. - Part A Toxic. /Hazard. Subst. Environ. Eng. 48, 1264-1271. https://doi.org/10.1080/ 10934529.2013.776898.

Nikolaou, A., Meric, S., Fatta, D., 2007. Occurrence patterns of pharmaceuticals in water and wastewater environments. Anal. Bioanal. Chem. 387, 1225-1234. https://doi. org/10.1007/s00216-006-1035-8.

Petrie, B., Barden, R., Kasprzyk-Hordern, B., 2015. A review on emerging contaminants in wastewaters and the environment: Current knowledge, understudied areas and recommendations for future monitoring. Water Res 72, 3-27. https://doi.org/ 10.1016/j.watres.2014.08.053.

Pocostales, P., Álvarez, P., Beltrán, F.J., 2011. Catalytic ozonation promoted by aluminabased catalysts for the removal of some pharmaceutical compounds from water. Chem. Eng. J. 168, 1289-1295. https://doi.org/10.1016/j.cej.2011.02.042.

Radjenović, J., Petrović, M., Barceló, D., 2009. Fate and distribution of pharmaceuticals in wastewater and sewage sludge of the conventional activated sludge (CAS) and advanced membrane bioreactor (MBR) treatment. Water Res 43, 831-841. https:// doi.org/10.1016/j.watres.2008.11.043.

Ramírez-Malule, H., Quiñones-Murillo, D.H., Manotas-Duque, D., 2020. Emerging contaminants as global environmental hazards. A bibliometric analysis. Emerg. Contam. 6, 179-193. https://doi.org/10.1016/j.emcon.2020.05.001.

Ravikovitch, P.I., Neimark, A.V., 2001. Characterization of micro- and mesoporosity in SBA-15 materials from adsorption data by the NLDFT method. J. Phys. Chem. B. 105, 6817-6823. https://doi.org/10.1021/jp010621u.

Reddy P.V., Reddy S.V., Reddy B.S., ScienceDirect, 32016 1752-1761.

Rivas, J., Gimeno, O., Encinas, A., Beltrán, F., 2009. Ozonation of the pharmaceutical compound ranitidine: reactivity and kinetic aspects. Chemosphere 76, 651-656. https://doi.org/10.1016/j.chemosphere.2009.04.028.

Rosal, R., Rodríguez, A., Gonzalo, M.S., García-Calvo, E., 2008. Catalytic ozonation of naproxen and carbamazepine on titanium dioxide. Appl. Catal. B Environ. 84, 48-57. https://doi.org/10.1016/j.apcatb.2008.03.003.

Rout, P.R., Zhang, T.C., Bhunia, P., Surampalli, R.Y., 2021. Science of the Total Environment Treatment technologies for emerging contaminants in wastewater treatment plants : a review. Sci. Total Environ. 753, 141990 https://doi.org/ 10.1016/j.scitotenv.2020.141990.

Sánchez-Polo, M., Von Gunten, U., Rivera-Utrilla, J., 2005. Efficiency of activated carbon to transform ozone into. $\mathrm{OH}$ radicals: influence of operational parameters. Water Res 39, 3189-3198. https://doi.org/10.1016/j.watres.2005.05.026. 
Schmitt, G.L., Pietrzyk, D.J., 1985. Liquid Chromatographic separation of inorganic anions on an alumina column. Anal. Chem. 57, 2247-2253. https://doi.org/ 10.1021/ac00289a017.

Shah, A.I., Din Dar, M.U., Bhat, R.A., Singh, J.P., Singh, K., Bhat, S.A., 2020. Prospectives and challenges of wastewater treatment technologies to combat contaminants of emerging concerns. Ecol. Eng. 152, 105882 https://doi.org/10.1016/j. ecoleng.2020.105882.

Shariati, F.P., Mehrnia, M.R., Salmasi, B.M., Heran, M., Wisniewski, C., Sarrafzadeh, M. H., 2010. Membrane bioreactor for treatment of pharmaceutical wastewater containing acetaminophen. Desalination 250, 798-800. https://doi.org/10.1016/j. desal.2008.11.044.

Skoumal, M., Cabot, P.L., Centellas, F., Arias, C., Rodríguez, R.M., Garrido, J.A., Brillas, E., 2006. Mineralization of paracetamol by ozonation catalyzed with $\mathrm{Fe} 2+$ Cu2+ and UVA light. Appl. Catal. B Environ. 66, 228-240. https://doi.org/10.1016/ j.apcatb.2006.03.016.

Yang, L., Yu, L.E., Ray, M.B., 2009. Photocatalytic oxidation of paracetamol: dominant reactants, intermediates, and reaction mechanisms. Environ. Sci. Technol. 43, 460-465. https://doi.org/10.1021/es8020099.
Yang, Y., Ok, Y.S., Kim, K.H., Kwon, E.E., Tsang, Y.F., 2017. Occurrences and removal of pharmaceuticals and personal care products (PPCPs) in drinking water and water/ sewage treatment plants: a review. Sci. Total Environ. 596-597, 303-320. https:// doi.org/10.1016/j.scitotenv.2017.04.102.

Yuan, X., Duan, S., Wu, G., Sun, L., Cao, G., Li, D., Xu, H., Li, Q., Xia, D., 2018. Enhanced catalytic ozonation performance of highly stabilized mesoporous ZnO doped g-C3N4 composite for efficient water decontamination. Appl. Catal. A Gen. 551, 129-138. https://doi.org/10.1016/j.apcata.2017.12.011.

Zeng, Y.F., Liu, Z.L., Qin, Z.Z., 2009. Decolorization of molasses fermentation wastewater by SnO2-catalyzed ozonation. J. Hazard. Mater. 162, 682-687. https://doi.org/ 10.1016/j.jhazmat.2008.05.094.

Zhang, T., Li, C., Ma, J., Tian, H., Qiang, Z., 2008. Surface hydroxyl groups of synthetic $\alpha$-FeOOH in promoting radical dot\}OH generation from aqueous ozone: Property and activity relationship. Appl. Catal. B Environ. 82, 131-137. https://doi.org/ 10.1016/j.apcatb.2008.01.008.

Zhong, X., Yang, B., Zhang, X., Jia, J., Yi, G., 2012. Effect of calcining temperature and time on the characteristics of Sb-doped SnO 2 nanoparticles synthesized by the solgel method. Particuology 10, 365-370. https://doi.org/10.1016/j. partic.2011.09.005. 